1

2

3

4

5

6

\section{Dysregulated heparan sulfate proteoglycan metabolism promotes Ewing sarcoma tumor growth}

\author{
Elena Vasileva ${ }^{1}$, Mikako Warren ${ }^{2,3}$, Timothy J. Triche ${ }^{2,3}$, James F. Amatruda ${ }^{1,4,5, *}$
}

${ }^{1}$ Cancer and Blood Disease Institute, ${ }^{2}$ Division of Pathology and Laboratory Medicine, Children's Hospital Los Angeles, Los Angeles, CA;

${ }^{3}$ Department of Pathology, ${ }^{4}$ Department of Pediatrics, ${ }^{5}$ Department of Medicine, Keck School of Medicine, University of Southern California, Los Angeles, CA.

*Correspondence to jamatruda@ chla.usc.edu 


\section{Abstract}

21 The Ewing sarcoma family of tumors is a group of malignant small round blue cell tumors

22 (SRBCTs) that affects children, adolescents and young adults. The tumors are characterized by

23 reciprocal chromosomal translocations that generate chimeric fusion oncogenes, the most

24 common of which is EWSR1-FLI1. Survival is extremely poor for patients with metastatic or

25 relapsed disease, and no molecularly-targeted therapy for this disease currently exists. The

26 absence of a reliable genetic animal model of Ewing sarcoma has impaired investigation of

27 tumor cell/microenvironmental interactions in vivo. We have developed a new genetic model of

28 Ewing sarcoma based on Cre-inducible expression of human EWSR1-FLI1 in wild type

29 zebrafish, which causes rapid onset of SRBCTs at high penetrance. The tumors express

30 canonical EWSR1-FLI1 target genes and stain for known Ewing sarcoma markers including

31 CD99. Growth of tumors is associated with activation of the MAPK/ERK pathway, which we

32 link to dysregulated extracellular matrix metabolism in general and heparan sulfate catabolism in

33 particular. Targeting heparan sulfate proteoglycans with the specific heparan sulfate antagonist

34 Surfen reduces ERK1/2 signaling and decreases tumorigenicity of Ewing sarcoma cells in vitro

35 and in vivo. These results highlight the important role of the extracellular matrix in Ewing

36 sarcoma tumor growth and the potential of agents targeting proteoglycan metabolism as novel

37 therapies for this disease. 
Ewing sarcoma is an aggressive sarcoma of bone and soft tissue with a peak incidence in adolescents and young adults (Gaspar et al., 2015). Diagnosis relies on histologic and molecular analysis of biopsy specimens or surgically resected tumor tissue. Histologic examination of the tumor typically reveals sheets of small, round, blue cells with a prominent nucleus and scant

43 cytoplasm. Approximately $20-25 \%$ of patients present with metastases at diagnosis that are often

44 resistant to intensive therapy (Gaspar et al., 2015). Standard multimodal therapy for patients with small round blue cell tumor (SRBCT) includes surgical resection and/or local radiotherapy as well as intensive multi-agent chemotherapy (Grünewald et al., 2018). Ewing sarcoma family tumors are characterized by the presence of reciprocal chromosomal translocations that fuse a member of the FET family of RNA-binding proteins (encoded by FUS, EWSR1 and TAF15), with different members of the ETS (E26-specific) family of transcription factors. The most common oncofusion found in $85 \%$ of cases is EWSR1-FLI1(Delattre et al., 1992; Grünewald et al., 2018). These chimeric fusion oncoproteins act as aberrant transcription factors deregulating hundreds of genes (for example, genes involved in cell-cycle regulation, cell migration and proliferation) by binding DNA enriched with GGAA motifs (Gangwal et al., 2008; Guillon et al., 2009; Johnson et al., 2017). These and other studies, made on patient-derived tumor tissue and cell lines, have provided great insight into the molecular mechanisms of fusion protein function. However, in the absence of a representative in vivo model, other questions, including the cell of origin of Ewing sarcoma, mechanisms of tumor initiation and the relationships between tumor and host cells, remain a subject of constant debate.

ERK1 and ERK2 are key effectors in the Ras-Raf-MEK-ERK signal transduction cascade. The phosphorylation of ERK1/2 is required for the activation and subsequent phosphorylation of hundreds of cytoplasmic and nuclear substrates including transcription factors regulating cell adhesion, migration, and proliferation (Meloche and Pouysségur, 2007). ERK1/2 activity is required for transformation of NIH-3T3 cells by EWSR1-FLI1 (Silvany et al., 2000). In therapynaive Ewing sarcoma samples, combined expression of pAKT, pmTOR, and pERK predicted worse progression-free and overall survival (Van De Luijtgaarden et al., 2013). ERK is a downstream target of Insulin-like growth factor signaling, however the prognostic impact of

68 IGF-1 and IGF-1 receptor expression in Ewing sarcoma is controversial (Scotlandi et al., 2011).

69 These findings raise the question of precisely which mechanisms drive ERK1/2 signaling in

70 Ewing sarcoma, including the possible role of the tumor microenvironment. 
72 The tumor microenvironment (TME) plays an important role in determining tumor cell growth,

73 survival, and response to treatment. The tumor microenvironment is composed of various cell

74 types embedded in an altered extracellular matrix (ECM). The ECM is a three-dimensional

75 network of extracellular proteins, collagen, glycoproteins and signaling molecules that provide

76 structural and biochemical support to surrounding cells, as well as playing an essential role in

77 signal transduction (Kim et al., 2011). Proteoglycans are key molecular effectors of the cell

78 surface and pericellular microenvironment with essential roles in signal transduction and

79 regulating cell adhesion, migration and differentiation. Signaling between cells is modulated by

80 proteoglycan activity at the cell membrane (Elfenbein and Simons, 2010). They have an ability

81 to interact with both ligands and receptors that could directly affect cancer growth (Edwards,

82 2012; Iozzo and Sanderson, 2011; Multhaupt et al., 2016; Mythreye and Blobe, 2009).

83 Importantly heparan sulfate proteoglycans play an essential role in differentiation and migration

84 of both neural crest and mesenchymal cells - both of them are considered as potential cell of

85 origin of Ewing sarcoma (Henderson and Copp, 1997; Long and Huttner, 2019; Papy-Garcia and

86 Albanese, 2017; Yaylaci et al., 2016). To date, however, little is known about the role of

87 proteoglycans and activation of ERK1/2 signaling in Ewing sarcoma development.

A genetic animal model of Ewing sarcoma family of tumors would thus be highly valuable as a complement to existing xenograft models for exploration of cooperating genetic factors for

91 tumor development and for testing the role of the complex microenvironment in tumor

92 progression. However, multiple attempts to create genetically-engineered mouse models of

93 Ewing sarcoma have not yielded a tractable model, likely due to the developmental toxicity of

94 heterotopic expression of the oncofusion (Minas et al., 2017). Previously we demonstrated that

95 transposon-mediated expression of human EWSRI-FLII drives small round blue cell tumor

96 formation in zebrafish from 6 to 19 months of age (Leacock et al., 2012). While serving as proof

97 of principle that EWSR 1-FLII is tumorigenic in fish, the model had some limitations, including

98 low penetrance, requirement for tp53 deficiency, and a low incidence of other tumor types such

99 as leukemias.

101 Here we describe Cre-inducible invasive model of Ewing Sarcoma in zebrafish that reproducibly

102 develops tumors in wild type backgrounds. We characterize tumors and show that they

103 recapitulate the main aspects of the human disease. Using this model, we show that tumor 
104 growth is associated with activation of the ERK1/2 signaling pathway, and that EWSR1-FLI1

105 upregulates expression of proteins involved in extracellular matrix reorganization and heparan

106 sulfate proteoglycan catabolism. We demonstrate that Surfen, a heparan sulfate antagonist,

107 effectively reduces proteoglycan-mediated activation of ERK1/2 signaling in Ewing sarcoma cell

108 lines and zebrafish models, leading to decreased proliferation of Ewing sarcoma tumor cells in

109 vitro and in vivo.

\section{Results}

\section{Cre-inducible expression of $E$ WSR 1-FLI1 drives SRBCT development in zebrafish.}

113 We reasoned that the low penetrance of tumors and requirement for loss of tp53 function in our

114 original zebrafish Ewing sarcoma model (Leacock et al., 2012) might be due to developmental

115 toxicity of EWSR1-FLI1, similar to what was described in mouse models (Minas et al., 2017).

116 This is especially true since microinjection is performed into single cell-stage embryos, allowing

117 integration of transposons into cell populations early in development. We therefore tested several

118 strategies, beginning with expression of EWSRI-FLII under ubiquitous and tissue specific

119 promoters in wild type zebrafish embryos (Fig. 1A). All constructs incorporated eGFP linked to

120 EWSR1-FLI1 via a viral 2A linkage, to allow fluorescent labeling of EWSR1-FLI1-expressing

121 cells via an unfused eGFP (Provost et al., 2007). Consistent with our previous data (Leacock et

122 al., 2012), constitutive expression of eGFP-2A-EWSRI-FLI1 under the beta-actin promoter in

123 wildtype fish caused high embryonic lethality and low incidence of tumor formation. We

124 obtained similar results with other ubiquitous promoters including $c m v$ and ubiquitin (ubi). On

125 the other hand, expression of EWSR1-FLII from tissue-specific promoters (sox $9 b$, flila and

126 mitfa) failed to produce tumors (Supplemental Fig.1A). These promoters become active only

127 during somitogenesis or at later stages, suggesting that the developmental stages or lineages

128 marked by these promoters were no longer susceptible to transformation by EWSRI-FLII.

129 Based on these results, we suspected that at early stages of development, beyond the initial pre-

130 gastrulation stage but prior to the onset of somitogenesis, there might be a population of cells

131 that would be susceptible to transformation. We accordingly designed a Cre-inducible allele

132 (loxP-DsRed-STOP-loxP-GFP-2A-EWSR1-FLI1, henceforth Red-STOP-Green or “RSG”-

133 EWSR1-FLI1) that would allow more control over the timing of EWSR1-FLII expression.

134 Injection of RSG-EWSR1-FLII transposon and Tol2 transposase, along with mRNA encoding

135 Cre, allows for a short delay in expression of EWSRI-FLI1, as the Cre mRNA must be translated

136 before recombination can occur. Initial attempts to generate tumors with RSG-EWSRI-FLII 
137 driven by the beta-actin promoter (Supplemental Fig. 1B, 2B,C) caused early apoptosis

138 (Supplemental Fig. 2A) and the growth of cranial cell masses (Supplemental Fig. 2D), however

139 failed to recapitulate the histologic appearance of Ewing sarcoma (Supplemental Fig. 2E).

140 In contrast, co-injections of Cre mRNA with expression constructs in which RSG-EWSR1-FLI1

141 is driven by the ubiquitin promoter led to robust, mosaic expression of EWSRI-FLII and GFP

142 (Fig.1 A, B). To estimate the frequency of tumor development using this approach, injected fish

143 were sorted for GFP at 14 days post fertilization (dpf) and a cohort of 77 fish was monitored up

144 to 4 months. To control for promoter leakiness, we injected embryos with ubi:RSG-EWSR1-FLII

145 in the presence of GFP RNA (142 fish). Uninjected embryos were used as an additional negative

146 control (150 fish). We found that $34 \%$ of GFP positive fish developed tumors (Fig. 1C,

147 Supplemental Table 1) exhibiting SRBCT histology (Fig. 1D, Supplemental Fig. 3C). No tumors

148 were observed in either control group. Among the fish developing tumors, $42 \%$ developed a

149 single tumor, while $58 \%$ of fish had 2 or more tumors (Supplemental Fig. 3A, Table 1). EWSR1-

150 FLII driven tumors arose most frequently in the dorsal regions of the fish (Fig. 1E). 37\% of

151 tumors were SRBCTs associated with the dorsal fin radial bones, while a further $15 \%$ of tumors

152 arising from similar locations showed deep muscle invasiveness and were characterized as

153 SRBCT with diffuse striated muscle infiltration. $9 \%$ and $21 \%$ of tumors were associated with the

154 skeleton of caudal and anal fins, respectively. Finally, we observed several tumors that appeared

155 to arise from the cranial skeleton or the brain. In summary, the inducible ubi:GFP2A-EWSR1-

156 FLII allele efficiently induced bone and soft-tissue small round blue cell sarcomas in fish,

157 without requirement for impaired tp53 function.

\section{EWSR1-FLI1 driven tumors in zebrafish recapitulate the main aspects of human Ewing}

\section{0 sarcoma.}

161 To further characterize the zebrafish model, we performed immunohistochemistry (IHC) on

162 tumors with antibodies specific for human FLI1 and CD99 (Fig. 2A, Supplemental Fig. 4). As

163 expected, tumor cells had nuclear localization of EWSR1-FLI1, whereas control fish had no

164 expression of FLI1 in the corresponding sites (Supplemental Fig. 4 top panel). CD99 is a cell

165 surface glycoprotein that serves as a sensitive, clinically useful marker for Ewing sarcoma

166 (Muhammad et al., 2012). IHC confirmed the presence of CD99 on the cell surface of zebrafish

167 Ewing sarcoma tumor cells (Fig. 2A). Ewing sarcoma cells are characterized by presence of the

168 glycogen and are positive for Periodic acid-Schiff (PAS) staining (Muhammad et al., 2012). 
169 Consistently, zebrafish tumors were positive for PAS staining (Fig. 2B). NROB1 is a target of

170 EWSR1-FLI1 that directly modulates transcription and oncogenesis in Ewing sarcoma (Kelsey

171 C. Martin Mhatre V. Ho, 2009). Analysis of relative RNA expression showed upregulated

172 expression of $n r O b l$ in tumor tissues compared to normal (Fig. 2C), correlating with EWSRI-

173 FLI1 expression level in tumor samples. Recently, it was shown that Ewing sarcoma cells exhibit

174 cell to cell heterogeneity affecting proliferative and migratory potential of tumor cells (Franzetti

175 et al., 2017). To test whether zebrafish tumor cells express EWSR1-FLII on different levels we

176 performed immunofluorescence staining of tumor sections with anti-GFP and anti-FLI1

177 antibodies (Fig.2 D). GFP staining was used to label all tumor cells within the tumor, while FLI1

178 staining was implemented to detect the EWSR1-FLI oncofusion in tumor cells (Fig.2D). Staining

179 of zebrafish tumors showed that cells have varying levels of EWSR1-FLI1. Thus, the zebrafish

180 model appears to recapitulate the cell-to cell heterogeneity found in human Ewing Sarcoma cells.

181 To test whether tumors express EWSR1-FLI1 on the protein level we collected tumor tissues at

182 different sites (dorsal, caudal and pectoral fins) and processed them for immunoblot analysis. All

183 tumor samples expressed EWSR1-FLI1 (Fig. 2E). We next performed LC-MS/MS mass

184 spectrometry analysis of protein samples made from tumors located on dorsal fin, caudal fin and

185 pectoral fin. Normal tissues from the corresponding sites were used as controls. We first

186 identified a set of 194 proteins that were commonly upregulated in the zebrafish tumors

187 compared to control tissues (pval<0.05). To test the similarity of fish and human Ewing sarcoma,

188 we used gene set enrichment analysis (GSEA) (Subramanian et al., 2005) to test the enrichment

189 of the 194 genes in a publicly available RNA-seq dataset of 44 human Ewing sarcoma tumors

190 and 18 normal samples Series (GSE17674). As a further test of specificity, we compared the fish

191 tumors to another RNA-Seq dataset of 44 human rhabdomyosarcoma tumors and 5 normal

192 samples (GSE108022). GSEA showed enrichment of zebrafish tumor upregulated genes (NES =

193 1.501, FWER=0.029) in the human Ewing Sarcoma dataset but not in human rhabdomyosarcoma

194 (NES = -1.476, FWER=0.024). Taken together, the histologic appearance, marker expression

195 and gene expression establish the similarity of zebrafish EWSR1-FLI1-induced sarcomas to

196 human Ewing sarcoma.

\section{Characterization of embryonic model of ES}

198 To characterize the effects of EWSRI-FLII expression during early stages of zebrafish

199 development we integrated the ubi:RSG-EWSRI-FLII cassette into the zebrafish genome in the 
200 presence of Cre mRNA (Fig. 3A top panel). Negative controls included co-injection of Cre mRNA with an ubi:RSG construct that lacks EWSRI-FLII (Fig. 3A middle panel) and co-

202 injection of ubi:RSG-EWSR 1-FLI with GFP mRNA (Fig. 3A bottom panel). Embryos were

203 imaged at 12 hours post-fertilization (hpf), $24 \mathrm{hpf}$ and $5 \mathrm{dpf}$. The timeline demonstrates that GFP

204 driven by the ubi promoter is expressed broadly, including throughout the muscle (Fig. 3A,

205 middle panel). However, zebrafish expressing eGFP-2A-EWSRI-FLI under the $u b i$ promoter

206 have a distinct distribution pattern of GFP-positive cells (Fig. 3A upper panel), predominantly on

207 the fish dorsum, tail and fins (Fig. 3A upper panel).

208 In most murine models, EWSRI-FLI expression is toxic and causes embryonic lethality (Minas et 209 al., 2017). To estimate the developmental toxicity of EWSRI-FLII expression in zebrafish we 210 performed survival analysis in a group of 508 animals. Uninjected embryos $(\mathrm{N}=528)$, embryos

211 injected with ubi:RSG-EWSRI-FLII and GFP mRNA (N=318) and embryos injected with 212 ubi:RSG and Cre mRNA (N=298) were used as negative controls. Expression of EWSR1-FLII 213 significantly increased embryonic mortality in zebrafish (Fig. 3B).

214 To confirm the expression of EWSRI-FLII in the zebrafish embryo model, we collected embryos 215 expressing low (GFP+), medium (GFP++) and high (GFP+++) levels of EWSRl-FLII (Fig. 3C)

216 for analysis via qRT-PCR (Fig. 3D) or immunoblot (Fig. 3E). Upon Cre-mediated

217 recombination, EWSRI-FLI is efficiently expressed in embryos on both the RNA and protein 218 levels (Fig. 3 D,E).

219 In summary, the Cre-inducible allele leads to robust and reproducible expression of human

220 EWSR 1-FLI1 with limited spatial distribution during early zebrafish embryogenesis.

221 Developmental toxicity, while much less than that caused by EWSRI-FLI expression under $b$ 222 actin and $c m v$ promoters, does impact the survival of larvae over the first 10 days of life. adult tumors

225 Our finding that expression of EWSRI-FLII in early embryos leads to a high prevalence of 226 tumors in adult zebrafish led us to examine the behavior of cells expressing EWSRI-FLII in 227 developing embryos, to understand early events in tumorigenesis. Zebrafish embryos mosaically 228 expressing EWSR1-FLI1, but not control embryos, developed outgrowths visible as discrete cell 
masses. Immunostaining with anti-phospho-histone $\mathrm{H} 3(\mathrm{pH} 3)$ showed increased cell proliferation in these areas, associated with expression of EWSRI-FLII as indicated by the associated GFP marker (Fig. 4A). The Ras-MAPK-ERK signaling pathway transduces signals downstream of growth factor receptors, and is an important mediator of cell proliferation during embryonic development and in cancer (Kamiya et al., 2015; Maekawa et al., 2007; Steinmetz et al., 2004;

234 Wong et al., 2019; Yang et al., 2021; Zhou et al., 2019). To assess the contribution of MAPK-

235 ERK signaling to formation of outgrowths, we performed immunofluorescence staining for the

236 active, phosphorylated form of ERK1/2 (pERK1/2). Cells expressing EWSR1-FLI1 were positive 237 for pERK1/2 (Fig. 4B). While most pERK1/2-positive cells also expressed EWSRl-FLI1 (Fig.

238 4C), some surrounding cells lacking the transgene were also marked with pH3 and pERK1/2 239 (Supplemental Figure 5A). Thus, activation of ERK1/2 signaling is an early event in EWSR1-FLI 240 driven aberrations. To test whether the activation of ERK1/2 signaling could be found in mature

241 zebrafish tumors, we prepared histologic sections of tumors and performed

242 immunohistochemistry for pERK1/2 (Fig. 4D, Supplemental Figure 5B), complemented by 243 immunoblot analysis (Fig. 4E,F). Similar to EWSR1-FLI1 driven outgrowth in larvae, ERK1/2 is 244 active in advanced zebrafish tumors. ERK1/2 signaling activity in tumors was heterogeneous, 245 with focal areas showing more intense signaling activity.

\section{EWSR1-FLI1 affects proteoglycan metabolism in zebrafish embryonic model}

247 To gain further insight into the impact of EWSR I-FLII expression during early tissue and organ

248 development and the mechanisms driving increased growth factor signaling and cell

249 proliferation, we performed mass spectrometry analysis. As above, we integrated the $u b i: R S G$ -

250 EWSR1-FLI1 cassette into the zebrafish genome in the presence of Cre mRNA. The control

251 group of embryos was co-injected with an $u b i: R S G$ transposon and Cre mRNA. Embryos were

252 sorted for GFP expression at 24hpf and 48hpf time points and used to generate samples for LC-

253 MS/MS analysis. EWSR1-FLI1 significantly affects protein expression in zebrafish embryos

254 (Fig. 5A). We identified 248 differentially expressed proteins affected by EWSR1-FLI1 at 24hpf, 255 and 1102 at 48 hpf (Fig. 5B). Downregulated proteins comprised 65\% and $73 \%$ of differentially 256 expressed proteins at 24hpf and 48hpf, respectively, suggesting that EWSR1-FLI1 was acting 257 mostly as a transcriptional repressor rather than an activator (Fig. 5B).

258 Gene Ontology (GO) enrichment analysis of proteomics data at the 48hpf time point showed that 259 downregulated proteins were involved in regulation of cell metabolism (Fig. 5C, Supplemental 
Table 2). Importantly, we found a strong upregulation of proteins involved in Extracellular Matrix (ECM) reorganization, proteoglycan metabolism, and protein synthesis (Fig. 5D,

262 Supplemental Table 2). The proteomics data revealed that EWSR1-FLI1 expression in zebrafish

263 embryos is associated with upregulated expression of collagens colla1b, colla2, col2ala,

264 col9a1b, col9a2 and col28a2a (Supplemental Table 2), which are involved in ECM organization

265 and skeletal system development. Proteins involved in proteoglycan catabolism were also

266 significantly differentially expressed in embryos expressing EWSR1-FLI1 (Fig.5E, Supplemental

267 Table 2). Among the top identified hits was N-sulfoglucosamine sulfohydrolase (sgsh), the

268 enzyme involved in heparan sulfate proteoglycan catabolism (Fig. 5E). We also found

269 upregulated gnsb and gnsa (N-acetylglucosamine-6-sulfatase) enzymes involved in hydrolysis of

270 Heparan sulfate chains (Supplemental Table 2).

271 To compare results obtained from proteomics data of Ewing sarcoma zebrafish model with those

272 from human Ewing sarcoma, we analyzed the profile of proteins associated with proteoglycan

273 metabolism from microarray data of 44 Ewing sarcoma samples and 18 normal tissue samples.

274 Expression of enzymes involved in proteoglycan metabolism was strongly upregulated in tumor

275 samples compared to normal tissue (Fig. 5F). Specifically, we found upregulation of enzymes

276 involved in the catabolism of heparan sulfate proteoglycans (including SGSH, GNS, HS3ST4,

277 HS3ST1, HS2ST1 and HS6ST1) in human Ewing sarcoma (Fig. 5F). Furthermore, proteoglycan

278 metabolism was also strongly dysregulated in Ewing sarcoma tissues.

279 Taken together, our genetic model of Ewing Sarcoma revealed that EWSR1-FLI1 expression

280 dysregulates normal protein expression starting from early zebrafish development. The

281 expression of EWSR1-FLI1 is associated with strong upregulation of ECM proteins and, most

282 notably, enzymes involved in heparan sulfate proteoglycan catabolism. Supporting these data, we

283 show that the genes involved in proteoglycan metabolism are strongly upregulated in human

284 Ewing sarcoma tumors.

\section{Surfen inhibits proteoglycan-mediated activation of ERK1/2}

286 Proteoglycans play a key regulatory role in the interactions of cells with ECM proteins, growth

287 factors and cytokines, and thus have major influence on cell signaling pathways that directly

288 affect cancer growth (Edwards, 2012; Iozzo and Sanderson, 2011; Multhaupt et al., 2016;

289 Mythreye and Blobe, 2009). Our finding that EWSRI-FLI expression is associated with altered 
proteoglycan expression and metabolism suggests that dysregulation of proteoglycans may contribute significantly to growth promoting signaling pathways in Ewing sarcoma, including

292 ERK signaling. Thus, proteoglycan metabolism could serve as a novel target for Ewing sarcoma.

293 To test these possibilities, we performed treatment of Ewing sarcoma cell lines with the small

294 molecule surfen (bis-2-methyl-4-amino-quinolyl-6-carbamide). Surfen is a sulfated heparan

295 sulfate antagonist with a high affinity to all sulfated GAGs (Schuksz et al., 2008). Surfen blocks

296 sulfation and degradation of GAG chains in vitro and affects growth factor binding and

297 proteoglycan-mediated signal transduction through certain cell surface growth factor receptors

298 (Schuksz et al., 2008).

First, we tested whether surfen can block proteoglycan-mediated activation of ERK1/2 signaling in the TC32 and EWS502 Ewing sarcoma cell lines. To reduce the basal level of ERK1/2

301 phosphorylation we performed pre-treatment of cells with serum-free media for 4 hours, and then

302 replaced serum-free media with the full-media in the presence of $1 \%$ DMSO or $2.5 \mu \mathrm{M}, 5 \mu \mathrm{M}$ or

$30310 \mu \mathrm{M}$ surfen. After 30 minutes of treatment, cell lysates were prepared and analyzed by

304 immunoblotting. Samples were normalized to the value of total ERK1/2. As expected, the

305 introduction of serum led to the activation of ERK1/2 signaling (Fig. 6 A,B). Addition of $5 \mu \mathrm{M}$

306 or $10 \mu \mathrm{M}$ surfen strongly significantly inhibited ERK1/2 phosphorylation (Fig. 6A, B). Thus,

307 blocking proteoglycan metabolism impairs ERK1/2 signaling in Ewing sarcoma cells.

308 We next tested the effect of surfen treatment on the proliferation rates of TC32 and EWS502 309 cells exposed to surfen or DMSO vehicle. Treatment with surfen significantly reduces the 310 proliferation rates of Ewing sarcoma cells (Fig. 6C). Importantly, treatment of cells with surfen 311 at $10 \mu \mathrm{M}$ resulted in a decrease of TC32 proliferation by $62.7 \%$, and EWS502 by $63.4 \%$ 312 compared to control cells treated with 0.2\% DMSO (Fig. 6C). Surfen treatment caused 313 morphological changes in TC32 and EWS502 cells (Fig. 6D), consistent with predicted effects 314 on cell adhesion.

315 To estimate cell survival and the ability of a single cell to grow into a colony we performed a 316 clonogenic assay under low-adhesive conditions. We seeded 500 cells/well in a 24 well low 317 adhesive plate treated with surfen or 1\% DMSO, under serum-deprived conditions. Serum was 318 added 12 hours later to stimulate growth factor-mediated signaling. The colony number was 319 analyzed after 2 or 3 weeks of incubation for TC32 and EWS502, respectively. Treatment of 
320 cells with surfen led to a significant reduction in colony number for both cell lines (Fig. 6E, F).

321 More specifically, the treatment of TC32 cell with $2.5 \mu \mathrm{M}$ surfen led to a $90.3 \%$ decrease of

322 colony number while treatment of EWS502 cells with $2.5 \mu \mathrm{M}$ surfen resulted in a $97.8 \%$

323 decrease of colony forming units. Thus, surfen targets the heparan sulfate proteoglycan-mediated

324 activation of ERK1/2 signaling in Ewing sarcoma cells, inhibiting cancer cell proliferation and

325 cell survival.

\section{Surfen inhibits EWSR1-FLI1 mediated growth in zebrafish model.}

328 We next tested whether surfen could inhibit the formation of EWSR1-FLI driven outgrowths in 329 vivo in our zebrafish model. As described above, we generated fish mosaically expressing 330 EWSR1-FLI1. Fish with GFP-positive outgrowths were identified at 24hpf and treated with at 2 $331 \mu \mathrm{M}$ surfen or 0.2\% DMSO. Fish were imaged after 24 and 48 hours of treatment (Fig. 7A).

332 Consistent with results on human cells, surfen inhibited outgrowth development in the zebrafish 333 embryo model of Ewing sarcoma.

334 To quantify the effect of surfen, we took advantage of the changes in fin morphology driven by 335 the EWSR1-FLI oncofusion during the first 5 days of zebrafish development. We noticed that 336 EWSR1-FLI1 expression is associated with distortion of the normally straight appearance of the 337 dorsal fin border (Fig. 7B). To measure the distortion of the fin we calculated the coefficient of 338 curvature (Ccurv), which measures the degree of deviation of the border from a straight line;

339 more irregular fins are characterized by higher Ccurv (Fig. 7D). We hypothesized that treatment 340 of fish with drugs targeting EWSRI-FLI -related pathways would result in the rescue of the fin 341 phenotype (Fig. 7C).

343 Applying this metric, surfen did not affect the fin shape of control fish (Fig. 7E). EWSRI-FLII

344 expression strongly increased the Ccurv, and surfen treatment of fish expressing EWSRl-FLI

345 resulted in significant rescue of the phenotype (Fig. 7E). Taken together, these results

346 demonstrate that surfen can modulate ERK1/2 signaling and Ewing sarcoma cell growth both in 347 vitro and in vivo. 


\section{Discussion}

350 Although Ewing sarcoma was first described over 100 years ago, there are few if any 351 molecularly targeted therapies for patients with metastatic or relapsed disease. Fewer than $30 \%$

352 of patients presenting with metastases survive for 5 years (Riggi et al., 2021). While great

353 progress has been made using cells, xenografts and PDX models, the development of

354 complementary Ewing sarcoma animal models remains crucial for the understanding of disease

355 biology in the complex developmental microenvironment. The importance of tumor

356 microenvironment and communication between cancerous and host cells has become evident as

357 essential for tumor formation and invasion. A better understanding of such mechanisms will

358 support the development of new approaches, targeting not just cancer cells, but the environment

359 around them.

360 Previous attempts by multiple groups to generate a mouse model of Ewing sarcoma were

361 complicated by the high embryonic toxicity of the driver oncofusion (Minas et al., 2017).

362 Consistent with this experience, we have tested a panel of ubiquitous and tissue specific

363 promoters to drive EWSRI-FLII expression in zebrafish embryos (Supplemental Fig.1 A, B). We

364 found that in most cases, expression of the oncogene causes cellular apoptosis, embryonic

365 lethality or developmental defects. Cre-inducible expression of EWSRI-FLI under $c m v$ and $b$ -

366 actin ubiquitous promoters did not result in a high incidence of tumor development. However,

367 we discovered that Cre-inducible expression of human EWSR 1-FLII under the ubiquitin

368 promoter was associated with less oncofusion toxicity in zebrafish larva. The pattern of Cre-

369 induced eGFP-2A-EWSR I-FLI expression was consistently different from Cre-induced GFP

370 expression driven by the same ubiquitin promoter, suggesting that EWSRI-FLI can be tolerated

371 by certain cell types while being toxic for others.

372 Human Ewing sarcoma can occur in any part of the body in bone or soft tissue, but not

373 endodermally or ectodermally derived tissue. It most commonly involves the pelvis and proximal

374 long bones (Riggi et al., 2021). In our model, based on mosaic integration of human EWSRI-

375 FLI1 into the zebrafish genome, formation of tumors was observed in association with

376 mesenchymally derived skeleton at the regions proximal to the base of pectoral, anal and caudal

377 fins, and at supraneurals. 58\% of fish had more than one tumor (Supplemental Fig.3 A, Table 1).

378 Interestingly, we observed the formation of ectopic fins driven by EWSRI-FLII (Supplemental

379 Fig.3 B) suggesting that EWSR1-FLI1 may potentially re-direct the differentiation program of 
transformed cells. This model presents several advances over our previously-reported zebrafish mosaic model of Ewing sarcoma (Leacock et al., 2012). In that model, on a wild type background only $0.6 \%$ of fish developed tumors during the 15 months, and tp53-deficiency was required for more penetrant tumor formation. (Leacock et al., 2012). $40 \%$ of affected fish developed leukemia-like tumors rather than sarcomas. In our new Cre-inducible mosaic model, the $34 \%$ of fish developed tumors. Only 1 fish out of 77 developed a leukemia-like SRBCT. These findings highlight the important role that the level and spatiotemporal distribution of EWSR 1-FLII expression play in efficient tumor generation.

To characterize tumors, we performed IHC staining for markers commonly used in diagnosis of human Ewing sarcoma. Staining of zebrafish tumors with antibodies against FLI1 showed that cells have different expression level of EWSRI-FLI, consistent with recent reports of cell to cell heterogeneity which affects proliferative and migratory potential of Ewing sarcoma cells

392 (Franzetti et al., 2017). While silencing of transgene expression in individual cells may occur, the

393 fact that GFP and EWSR 1-FLII are expressed from a single mRNA transcript, and GFP

394 expression is widely retained throughout the tumor, make this possibility less likely. Staining for 395 CD99 and PAS are widely used for Ewing sarcoma diagnosis in patients (Muhammad et al., 2012). CD99 is a cell surface transmembrane protein highly expressed in all Ewing's sarcomas. Zebrafish tumor cells were positive for CD99. Additionally, consistent with human data zebrafish tumors were positive for PAS which stains glycogen and polysaccharides enriched in Ewing sarcoma. We showed that the expression of $n r O b 1$ in tumor tissue is strongly upregulated resembling the human phenotype (Kinsey et al., 2006). Altogether, zebrafish tumors are positive for known Ewing sarcoma markers recapitulating the main features of the human disease.

Previous studies established that $91 \%$ of human tumors had proliferating populations of cells positive for ki67 marker. High proliferation index was predictive of poor overall survival independent of tumor site, tumor volume or metastasis at diagnosis (Brownhill et al., 2014). We identified increased proliferation in EWSR1-FLI1 driven outgrowths in the earliest stages of tumor formation. In a wide variety of cancers, the ERK1/2 signaling pathway is known to control cell proliferation. Moreover it was shown that ERK1 and ERK2 are constitutively activated in NIH 3T3 cells expressing EWSR 1-FLI1 as well as in several human Ewing's sarcoma tumorderived cell lines (Silvany et al., 2000). Consistent with these data, we identified activated phosphorylation of ERK1/2 in both EWSR 1-FLI1 expressing outgrowths and tumors in the in 
411 vivo zebrafish model. In summary, tumorigenesis in fish is associated with activation of ERK1/2 412 signaling.

413 To study the mechanisms underlying the activation of ERK1/2 triggered by EWSR1-FLI1 we 414 performed LC-MS/MS analysis. We discovered that that EWSR1-FLI1 affects expression of 415 proteins involved in ECM reorganization and proteoglycan catabolism. It is known that tumors 416 leverage ECM remodeling to create a microenvironment that promotes tumorigenesis and 417 metastasis. These tumor-driven changes support tumor growth, migration and invasion. Our data 418 show that expression of EWSRI-FLII is associated with the strong production of collagens 419 col1a1b, col1a2, col2a1a, col9a1b, col9a2, col28a2a both in embryos (Supplemental table 2) and 420 in advanced tumors (data not shown), suggesting the importance of specific matrix for tumor 421 development. We found a strong upregulation of proteins involved in proteoglycan catabolism in 422 human Ewing sarcoma (Fig. 4F). Interestingly, the upregulation of heparanase, the enzyme 423 involved in cleavage of the side chains of heparan sulfate proteoglycans, was reported in Ewing 424 sarcoma tumors correlating with poor prognosis in patients (Shafat et al., 2011). Thus, Ewing 425 sarcoma oncogenesis is associated with dysregulation of proteoglycan turnover.

426 Proteoglycans are important components of extracellular matrix regulating Wnt, Hedgehog, 427 TGF- $\beta$, FGFR and other signaling pathways. Proteoglycans stabilize ligand-receptor 428 interactions, creating potentiated ternary signaling complexes that regulate the signaling 429 pathways involved in cell proliferation, migration, adhesion and growth factor sensitivity 430 (Elfenbein and Simons, 2010). For example, binding of FGF to its signaling receptor requires 431 prior binding to the heparan sulfate side chains of the proteoglycans (Mythreye and Blobe, 432 2009). Thus, dysregulation of proteoglycan catabolism can result in aberrations in signal 433 transduction from cell surface receptors.

434 To block the aberrantly activated proteoglycan-mediated pathways in Ewing sarcoma we 435 targeted the binding of GAG chains with the ligands and signal molecules. Surfen (bis-2-methyl436 4-amino-quinolyl-6-carbamide) binds to heparan sulfate and other GAGs blocking the sulfation 437 and degradation of GAG chains in vitro (Schuksz et al., 2008). Surfen also affects responses 438 dependent on heparan sulfate such as growth factor binding and activation of downstream 439 signaling pathways (Schuksz et al., 2008). To target proteoglycan-mediated activation of 440 ERK1/2 signaling we treated TC32 and EWS502 cells with surfen. Surfen impaired Ewing 
441 sarcoma cell proliferation at all doses tested, with the strongest effects at 5 and $10 \mu \mathrm{M}$.

442 Concomitant with the effect on proliferation, ERK1/2 phosphorylation was downregulated at

443 these doses of surfen, indicating that Ewing sarcoma cell lines are very sensitive to surfen-

444 mediated blockage of cell surface receptor signaling.

445 To test whether surfen is effective in vivo in the zebrafish model we treated fish with outgrowths

446 via aqueous exposure to surfen at $2 \mu \mathrm{M}$. Surfen demonstrated remarkable inhibition of outgrowth

447 development in zebrafish larvae. Thus, surfen is effective against human Ewing sarcoma cells in

448 vitro and against tumor growth in the zebrafish model in vivo. Surfen was originally developed

449 for use in humans to facilitate depot insulin deposition (Umber et al., 1938), and has been tested

450 as an agent against glioblastoma tumor cells (Logun et al., 2019). Thus, targeting

451 glycosaminoglycan metabolism may represent a new therapeutic opportunity for Ewing sarcoma.

452 We quantified the effect of surfen in vivo using the fin coefficient of curvature Ccurv. We note

453 that this assay has great potential for high-throughput screening to identify additional drugs

454 targeting proteoglycan-mediated signaling in Ewing sarcoma.

455 Overall, here we present a new inducible zebrafish model of Ewing sarcoma. The advantage of

456 the model is the opportunity to study tumorigenesis in vivo, in a complex developmental

457 background. The system further allows study of tumor cell behavior using high-resolution

458 imaging and is effective for high-throughput drug screening. Our findings suggest that the

459 temporal expression of EWSRI-FLII is crucial for tumor development, supporting the existence

460 of a specific cell or lineage of origin for Ewing sarcoma. Our new EWSRI-FLI zebrafish model

461 of Ewing sarcoma emphasizes the role of proteoglycans mediating ERK1/2 signaling and growth

462 of tumor cells. Further investigation of the interactions between Ewing sarcoma and the tumor

463 microenvironment in vivo can provide critical insights that may lead to new therapies of the

464 disease.

\section{ACKNOWLEDGMENTS}

466 This project is funded by grant U54 CA231649-01-A1 from the National Cancer Institute and by 467 grants from the 1 Million 4 Anna Foundation and Curing Kids Cancer. We thank the Children's 468 Hospital Los Angeles Pathology and Cellular Imaging Cores, the UT Southwestern Medical 469 Center Proteomics Core, and the University of Southern California High-Performance 470 Computing Cluster for exceptional services and for their expertise. We grateful to Genevieve 
471 Kendall for productive discussions and help. JFA was previously supported by the Nearburg

472 Professorship of Pediatric Oncology Research at UT Southwestern.

\section{Methods}

\section{Zebrafish Husbandry}

475 Danio rerio were maintained according to industry standards in an AALAAC-accredited facility.

476 WIK wild type fish were obtained from the ZIRC (Zebrafish International Resource Center

477 (https://zebrafish.org).

\section{$478 \quad$ Plasmids and Cloning}

Human EWSR1-FLII coding sequence was provided by Chris Denny, University of California-

481 Los Angeles, USA (Leacock et al., 2012). The Gateway expression system (Invitrogen) was used

482 for generation of all constructs for expression in zebrafish (Kwan et al., 2007). EWSR1-FLI1

483 flanked by attB2r site (at 5'primer) and attB3 site (at 3'primer) was cloned into a 3'entry vector

484 according to the provided protocol (Kendall and Amatruda, 2016). The plasmids containing a 485 stop-dsRed-stop sequence were a generous gift from Eric Olson. Likewise dsRed-STOP-GFP-

486 2A-EWSR1-FLI1 coding sequence flanked by attB1 and attB2 sites was cloned into a middle 487 entry vector (Kwan et al., 2007). The ubi promoter was a kind gift from Len Zon (Addgene 488 \#27320) (Mosimann et al., 2011). The flil promoter was provided by Nathan Lawson (Addgene 489 \#31160 and \#26031), and the mitfa promoter by James Lister (Addgene \#81234) (Kendall et al.,

490 2018). The beta actin promoter, $c m v$ promoter were used for plasmids generation and expression 491 in zebrafish. The plasmids containing a GFP-2A sequence were a kind gift from Steven Leach, 492 and were sub-cloned into a middle entry Gateway expression system (Kendall et al., 2018). The 493 destination vector pDestTol2pA2 and 3' SV40 late poly A signal construct, were used for 494 construct generation by an LR reaction with LR Clonase II Plus (Invitrogen) (Kwan et al., 2007). 495 Transposase, GFP and Cre RNAs were synthesized from plasmids pCS2FA, pCS2-Cre.zf and 496 pCS2-GFP accordingly using the mMessage mMachine kit (Applied Biosystems/Ambion, Foster 497 City, CA). The constructs generated include: beta-actin-GFP2A-pA (Genevieve Kendall), beta498 actin-GFP2A-EWSR1-FLI1, ubi-eGFP-2A, ubi-GFP2A-EWSR1-FLI1, cmv-eGFP-2A, cmv499 GFP2A-EWSR1-FLI1, fli-eGFP-2A, FLI-GFP2A-EWSR1-FLI1, mitfa-eGFP-2A, mitfa-GFP2A500 EWSR1-FLI1, beta-actin-dsRed-stop-eGFP-2A-pA,beta-actin-dsRed-stop-eGFP-2A-EWSR1-

501 FLII, ubi-dsRed-stop-eGFP-2A, ubi-dsRed-stop-eGFP-2A -EWSR1-FLI1, cmv-dsRed-stop- 
eGFP-2A, cmv-dsRed-stop-eGFP-2A -EWSR1-FLI1, fli-dsRed-stop-eGFP-2A, fli-dsRed-stopeGFP-2A -EWSR1-FLI1, mitfa-dsRed-stop-eGFP-2A, mitfa-dsRed-stop-eGFP-2A -EWSRI-

504 FLI1.

\section{Zebrafish injections}

507 Zebrafish embryos were injected at the single-cell stage. The injection mixes contained $50 \mathrm{ng} / \mu \mathrm{L}$ 508 of Tol2 transposase mRNA, $10-50 \mathrm{ng} / \mu \mathrm{L}$ of described DNA constructs, $0.1 \%$ phenol red, and 509 0.3X Danieau's buffer. The injection mixes containing beta-actin-dsRed-stop-eGFP-2A-pA, 510 beta-actin-dsRed-stop-eGFP-2A -EWSRI-FLI1, ubi-dsRed-stop-eGFP-2A, ubi-dsRed-stop511 eGFP-2A-EWSR1-FLI1, cmv-dsRed-stop-eGFP-2A, cmv-dsRed-stop-eGFP-2A-EWSR1-FLI1, 512 fli-dsRed-stop-eGFP-2A, fli-dsRed-stop-eGFP-2A -EWSR1-FLI1, mitfa-dsRed-stop-eGFP-2A, 513 mitfa-dsRed-stop-eGFP-2A -EWSR1-FLI1 also contained 0.5 ng of Cre_RNA or GFP_RNA.

\section{Zebrafish embryo survival}

515 For survival analysis of embryos, fish were injected with $u b i: R S G-E W S R 1-F L I 1$; Cre_RNA or 516 control mixes ubi:RSG-EWSRI-FLI; GFP_RNA ubi:RSG; Cre_RNA. The total number of 517 injected fish was counted (the exact number of fish for each condition is indicated in the 518 respective legend), and then the resulting alive embryos subsequently determined during first 10 days. Survival curves were plotted using GraphPad Prism 8.4.3. Biological replicates N= 3 .

\section{Protein Identification by LC-tandem Mass Spectrometry}

521 Zebrafish embryos were injected with $u b i: R S G-E W S R 1-F L I 1$;Cre_RNA or $u b i$ :RSG;Cre_RNA.

522 Embryos were sorted for GFP at 24hpf and 48hpf time points. Sorted embryos were

523 dechorionated, dissociated by pestle homogenizer in RIPA buffer supplemented with 1x inhibitor 524 of proteases (Mini Protease Inhibitor Cocktail, cOmplete). Additionally, tumor or normal tissue 525 from dorsal, caudal and pectoral fins were dissected and processed in an analogous way. Protein 526 levels were analyzed using the BCA protein assay Kit (Thermo Scientific). Lysates were heated 527 at $95^{\circ} \mathrm{C}$ for 5 minutes and loaded on a $12 \%$ gel (BioRad). Gels were stained with Coomassie

528 Blue. Stained $1 \mathrm{~cm}$ bands were cut out of gels, sliced into $1 \mathrm{~mm}$ cubes and transferred to 1.5

529 Eppendorf tubes for submission. Data were pre-proceeded and provided by the UT Southwestern 530 Proteomics Core. Data were analyzed using an R package ROTS (Suomi et al., 2017) and

531 visualized in R. Gene Set enrichment analysis was performed using the GSEA software 
532 according the instructions provided https://www.gsea-msigdb.org/gsea. The experiment was

533 performed in 3 technical replicates for embryo samples and 3 biological replicates for tissue 534 samples.

Zebrafish tumor collection, processing for histology, and tumor incidence

Zebrafish were screened under a Nikon SMZ25 fluorescent stereomicroscope for the presence of

537 GFP positive tumors. Fish with tumors were humanely euthanized and fixed in $4 \%$

538 paraformaldehyde/1XPBS for $48 \mathrm{hrs}$ at $4^{\circ} \mathrm{C}$. They were de-calcified in 0.5M EDTA for 5 days,

539 processed and mounted in paraffin blocks for sectioning and further experiments. For tumor

540 incidence curves, zebrafish were injected and sorted for GFP at $14 \mathrm{dpf}$ and monitored for 4

541 months. Zebrafish with no GFP fluorescence were considered as negative for EWSR1-FLI-

542 dependent tumor formation. Zebrafish with tumors were collected and processed as described

543 earlier for hematoxylin and eosin staining. All tumors were reviewed by an experienced sarcoma 544 pathologist.

\section{Immunofluorescence}

In zebrafish embryo whole mounts, embryos at $72 \mathrm{hpf}$ were fixed overnight at $4{ }^{\circ} \mathrm{C}$ in $4 \%$ PFA in

547 1xPBS and processed according to a published protocol (Verduzco and Amatruda, 2011).

548 Zebrafish embryos were stained with primary antibodies directed against Phospho-p44/42

549 MAPK (Erk1/2) Thr202/Tyr204 (4370S, Cell Signaling) at 1:200, GFP (4B10) (2955, Cell

550 Signaling) at 1:300, or Phospho-Histone H3 (Ser10) (D7N8E) (53348, Cell Signaling) at 1:500.

551 The secondary antibodies used were Goat anti-Mouse IgG $(\mathrm{H}+\mathrm{L})$ Alexa Fluor Plus 488

552 (\# A32723, Thermo Fisher), Donkey anti-Rabbit IgG (H+L) Alexa Fluor 546 (A10040, Thermo

553 Fisher), Goat anti-Rabbit IgG(H+L) Alexa Fluor 405 (A31556, Thermo Fisher) at 1:500. The

554 staining was repeated at least 3 times.

IHC staining

556 Slides with paraffin embedded tissue sections were baked for 60 minutes at $60^{\circ} \mathrm{C}$, immersed with

557 xylene, $100 \%$ ethanol, $95 \%$ ethanol, $75 \%$ ethanol, distilled $\mathrm{H} 2 \mathrm{O}$ two times each for 5 minutes

558 each. Antigen retrieval was performed in Trilogy reagent (920P, Sigma) for 10 minutes in the

559 pressure cooker. Slides were cooled and blocked with 3\% H2O2 for 30 minutes, followed by

560 blocking with $1 \%$ BSA/1xPBST for $1 \mathrm{~h}$. Slides were incubated with primary antibodies Anti- 
561 CD99 antibody (ab108297, Abcam) at 1:200, Anti-FLI1 (ab15289, Abcam) at 1:100, anti-

562 Phospho-p44/42 MAPK (Erk1/2) Thr202/Tyr204 (4370S, Cell Signaling) at 1:200 overnight.

563 Secondary antibodies used were Anti-rabbit IgG, HRP-linked Antibody (7074S, Cell Signaling),

564 Anti-mouse IgG, HRP-linked Antibody (7076S, Cell Signaling). SignalStain® DAB Substrate

565 Kit \#8059 was used for chromogen staining according to manufacturer's instructions. Slides were

566 also stained with hematoxylin and eosin, dehydrated and mounted with permount mounting

567 media. The staining was repeated more than 3 times.

\section{$568 \quad$ Imaging}

569 Embryos were imaged at 12 hpf, 24 hpf, 48 hpf, 72 hpf, and 5 dpf on Nikon SMZ25 fluorescent

570 stereomicroscope. Images of whole mount immune-stained zebrafish were taken on a Keyence

571 BZ-X700 fluorescent microscope. Slides were imaged on a Keyence BZ-X700 fluorescent

572 microscope, Leica DM4000B and Zeiss LSN710.

\section{RNA extraction, cDNA synthesis, and qRT-PCR}

574 Fresh GFP positive tumor tissues or sorted dechorionated embryos were snap frozen in liquid

575 nitrogen. Frozen tissues and embryos were subjected to total RNA isolation using the RNeasy

576 Microkit manufacturer's instructions (Qiagen). The RT2 HT First Strand Synthesis kit

577 (QIAGEN) was used for cDNA reverse transcription from $200 \mathrm{ng}-1 \mu \mathrm{g}$ of total RNA. qRT-PCR

578 was performed on a CFX384 Touch Real-Time PCR Detection System using the SYBRGreen

579 Master Mix (BioRad). See Supplemental Table 3 for primer sequences. Error bars indicate

580 standard deviation. To determine significance a student's t-test was performed on normalized $\mathrm{Ct}$

581 replicates. The RT-PCR analysis was performed at least 3 times for each experiment in 3

582 technical replicates for each condition.

\section{Cell culture}

584 TC32 and EWS502 cell lines were the kind gift of Dr. Angelique Whitehurst. TC32 was

585 maintained in RPMI 1640 GlutaMAX with 10\% Fetal Bovine Serum (Sigma) and 1X Antibiotic-

586 Antimycotic (Gibco) at $37^{\circ} \mathrm{C}$ in $5 \% \mathrm{CO}_{2}$. EWS502 was maintained in RPMI 1640 GlutaMAX

587 with $15 \%$ FBS (Sigma) and $1 \mathrm{X}$ Antibiotic-Antimycotic (Gibco) at $37^{\circ} \mathrm{C}$ in $5 \% \mathrm{CO}_{2}$. 


\section{Surfen treatment}

Surfen hydrate, $\geq 98 \%$ was obtained from Sigma-Aldrich (S6951). Because Surfen binds avidly to plastic, it is necessary to use glass vessels or precoat all plasticware with serum before use.

591 Surfen stock solutions were prepared in DMSO at $1 \mathrm{mM}$ and $5 \mathrm{mM}$, aliquoted and stored in glass containers at $-20^{\circ} \mathrm{C}$ in the dark.

\section{Zebrafish treatment with surfen}

594 For zebrafish treatment working solutions were prepared by diluting stock solutions in E3

595 medium. Final concentrations for treatments were determined as $2 \mu \mathrm{M}$ for surfen hydrate (S6951,

596 Sigma-Aldrich), based on maximal non-toxic concentrations for zebrafish embryos (Naini and

597 Soussi-Yanicostas, 2018). Control fish were treated with 0.2\% DMSO. Embryos were injected,

598 screened for GFP at $24 \mathrm{hpf}$, dechorionated and incubated for 2 days in $10 \mathrm{ml}$ of either control

599 medium (E3 medium containing 0.2\% DMSO) or E3 medium with 2mM surfen in a glass

600 beaker. All solutions were changed daily. Biological replicates $\mathrm{N}=4$. The exact number of fish

601 for each condition is indicated on figure legend.

\section{Protein extraction and western blots}

603 Cells or tumor tissues were harvested and lysed in RIPA buffer complemented with cOmplete

604 Mini Protease Inhibitor Cocktail inhibitors and Phosphatase inhibitor cocktails (Sigma). Lysates

605 were denatured by boiling in $1 \mathrm{x}$ Laemmli buffer at $95^{\circ} \mathrm{C}$ for 5 minutes and loaded on a 4-20\%

606 gradient gel (BioRad). PVDF membranes were used for proteins wet transfer (Bio-Rad).

607 Membranes were blocked in Casein $+0.1 \%$ Tween-20 (Thermo), and incubated overnight at $4{ }^{\circ} \mathrm{C}$

608 with the primary antibodies Phospho-p44/42 MAPK (Erk1/2) (Thr202/Tyr204) (4370S, Cell

609 Signaling) at 1:2000, p44/42 MAPK (Erk1/2) (137F5) (4695S, Cell signaling) at 1:2000, $\beta$-Actin

610 Antibody (4967S, Cell Signaling) at 1:2000, $\alpha$-Tubulin Antibody (2144S, Cell Signaling) at

611 1:2000. Secondary antibody used were Anti-rabbit IgG, HRP-linked Antibody (7074S, Cell

612 Signaling) at 1:5000, Anti-mouse IgG, HRP-linked Antibody (7076S, Cell Signaling) at 1:5000.

613 Signal was detected using SuperSignal West Pico Chemiluminescent Substrate (Fisher). BioRad

614 GelDoc XR was used for membranes imaging. The western blot analysis was performed at least

6153 times for each experiment in 3 technical replicates. 


\section{Cellular proliferation assays}

617 For proliferation TC32 and EWS502 were seeded at 2,000 cells per well of 96-well plate with 618 three replicas per timepoint in 10\% and 15\% RPMI 1640 GlutaMAX media supplemented with 619 1X Antibiotic-Antimycotic (Gibco). Cells were treated with 1.75uM, 2.5uM, 5uM and $10 \mathrm{uM}$ of 620 Surfen or $0.025 \%, 0.05 \%, 0.1 \%, 0.2 \%$ DMSO on 2 nd, 4 th, 6 th, 8 th days. The number of cells at

621 each point was measured using the hemocytometer at 1st, 3rd, 5th, 7th, 9th days. The

622 proliferation assay was performed at least 2 times. Three technical replicates were performed per 623 condition.

\section{Colony formation assay}

625 For colony formation assay 500 of TC32 and EWS502 cells were seeded per well of 24 wells 626 low adhesive plate treated with $0.5 \mathrm{uM}, 1 \mathrm{uM}, 1.5 \mathrm{um}, 2 \mathrm{uM}$, and $2.5 \mathrm{uM}$ of surfen or $1 \%$ DMSO 627 under serum-deprived conditions. Serum was added 12 hours later. Medium with surfen or 628 DMSO was changed 3 times a week. The colony number was analyzed on day 14 and 21 for 629 TC32 and EWS502 accordingly. For imaging media was removed, cells were pre-fixed and 630 stained with $0.5 \%$ crustal violet. The colony formation assay was performed at least 2 times. 631 Four technical replicates were performed per condition.

\section{Ccurvature calculation}

633 To measure the distortion of the fin we introduced the coefficient of curvature Ccurv=(L1$634 \mathrm{~L} 0) / \mathrm{L} 0 * 100$, where L1 is the length of the fin border between points $\mathrm{A}$ and $\mathrm{B}$ and L0 is the 635 length of the straight line between those two points (Fig7 C).

\section{Statistics}

637 Statistical analysis for embryonic survival, tumor incidence curves, proliferation curves, colony 638 formation, relative gene expression, were performed using GraphPad Prism 8.4.3 (La Jolla, CA).

639 The number of individual experiments, replicas and samples analyzed, and significance are

640 reported in the figure legends. Statistical significance was calculated by Student's t-test for two641 group comparison, one-way ANOVA for comparison of multiple groups with one control group 642 and for comparison between different experimental groups. p $>0.05=$ n.s, $\mathrm{p}<0.05={ }^{*}, \mathrm{p}<0.01=$ $643 * *, \mathrm{p}<0.001=* * *$ and $\mathrm{p}<0.0001=* * * *$. 


\section{References}

645

Brownhill S, Cohen D, Burchill S. 2014. Proliferation index: A continuous model to predict prognosis in patients with tumours of the Ewing's sarcoma family. PLoS One $\mathbf{9}$. doi:10.1371/journal.pone.0104106

Delattre O, Zucman J, Plougastel B, Desmaze C, Melot T, Peter M, Kovar H, Joubert I, de Jong P, Rouleau G, Aurias A, Thomas G. 1992. Gene fusion with an ETS DNA-binding domain caused by chromosome translocation in human tumours. Nature 359:162-165. doi: $10.1038 / 359162 \mathrm{a} 0$

Edwards IJ. 2012. Proteoglycans in prostate cancer. Nat Rev Urol 9:196-206. doi:10.1038/nrurol.2012.19

Elfenbein A, Simons A. 2010. Auxiliary and Autonomous Proteoglycan Signaling Networks. Methods Enzym 480:3-31. doi:10.1016/S0076-6879(10)80001-1

Franzetti GA, Laud-Duval K, Van Der Ent W, Brisac A, Irondelle M, Aubert S, Dirksen U, Bouvier C, De Pinieux G, Snaar-Jagalska E, Chavrier P, Delattre O. 2017. Cell-to-cell heterogeneity of EWSR1-FLI1 activity determines proliferation/migration choices in Ewing sarcoma cells. Oncogene 36:3505-3514. doi:10.1038/onc.2016.498

Gangwal K, Sankar S, Hollenhorst PC, Kinsey M, Haroldsen SC, Shah AA, Boucher KM, Watkins WS, Jorde LB, Graves BJ, Lessnick SL. 2008. Microsatellites as EWS / FLI response elements in Ewing' s sarcoma. PNAS 105:10149-54. doi:10.1073/pnas.0801073105

Gaspar N, Hawkins DS, Dirksen U, Lewis IJ, Ferrari S, Le Deley MC, Kovar H, Grimer R, Whelan J, Claude L, Delattre O, Paulussen M, Picci P, Hall KS, Van Den Berg H, Ladenstein R, Michon J, Hjorth L, Judson I, Luksch R, Bernstein ML, Marec-Bérard P, Brennan B, Craft AW, Womer RB, Juergens H, Oberlin O. 2015. Ewing sarcoma: Current management and future approaches through collaboration. J Clin Oncol 33:3036-3046. doi: 10.1200/JCO.2014.59.5256

Grünewald T, Cidre-Aranaz F, Surdez D, Tomazou E, Álava De E, Heinrich K, Sorensen P, Delattre O, Dirksen U. 2018. Ewing sarcoma. Nat Rev Dis Prim 4(1). doi:10.1038/s41572018-0003-X

Guillon N, Tirode F, Boeva V, Zynovyev A, Barillot E, Delattre O. 2009. The oncogenic EWSFLI1 protein binds in vivo GGAA microsatellite sequences with potential transcriptional activation function. PLoS One 4:e4932. doi:10.1371/journal.pone.0004932

Henderson DJ, Copp AJ. 1997. Role of the extracellular matrix in neural crest cell migration. $J$ Anat 191:507-515. doi:10.1046/j.1469-7580.1997.19140507.x

Iozzo R V., Sanderson RD. 2011. Proteoglycans in cancer biology, tumour microenvironment and angiogenesis. J Cell Mol Med 15:1013-1031. doi:10.1111/j.1582-4934.2010.01236.x

Johnson KM, Taslim C, Saund RS, Lessnick SL. 2017. Identification of two types of GGAAmicrosatellites and their roles in EWS/FLI binding and gene regulation in Ewing sarcoma. PLoS One 12:e0186275. doi:10.1371/journal.pone.0186275

Kamiya A, Ito K, Yanagida A, Chikada H, Iwama A, Nakauchi H. 2015. MEK-ERK activity regulates the proliferative activity of fetal hepatoblasts through accumulation of p16/19. Stem Cells Dev 24:2525-2535. doi:10.1089/scd.2015.0015 
686

687

688

689

690

691

692

693

694

695

696

697

698

699

700

701

702

703

704

705

706

707

708

Kelsey C. Martin Mhatre V. Ho J-AL. 2009. EWS/FLI and its Downstream Target NR0B1 Interact Directly to Modulate Transcription and Oncogenesis in Ewing's Sarcoma. Cancer Res 69:9047-9055. doi:10.1158/0008-5472.CAN-09-1540

Kendall GC, Amatruda JF. 2016. Chapter 9 Zebrafi sh as a Model for the Study of Solid Malignancies. Methods Mol Biol 1451:121-142. doi:10.1007/978-1-4939-3771-4

Kendall GC, Watson S, Xu L, Lavigne CA, Murchison W, Rakheja D, Skapek SX, Tirode F, Delattre O, Amatruda JF. 2018. PAX3-FOXO1 transgenic zebrafish models identify HES3 as a mediator of rhabdomyosarcoma tumorigenesis. Elife 7:e33800. doi:10.7554/eLife.33800

Kinsey M, Smith R, Lessnick SL. 2006. NR0B1 is required for the oncogenic phenotype mediated by EWS/FLI in Ewing's sarcoma. Mol Cancer Res 4:851-859. doi:10.1158/15417786.MCR-06-0090

Kwan KM, Fujimoto E, Grabher C, Mangum BD, Hardy ME, Campbell DS, Parant JM, Yost HJ, Kanki JP, Chien C. 2007. The Tol2kit : A Multisite Gateway-Based Construction Kit for Tol2 Transposon Transgenesis Constructs. Dev Dyn 236:3088-3099. doi:10.1002/dvdy. 21343

Leacock SW, Basse AN, Chandler GL, Kirk AM, Rakheja D, Amatruda JF. 2012. A zebrafish transgenic model of Ewing 's sarcoma reveals conserved mediators of EWS-FLI1 tumorigenesis. Dis Model Mech 5:95-106. doi:10.1242/dmm.007401

Logun MT, Wynens KE, Simchick G, Zhao W, Mao L, Zhao Q, Mukherjee S, Brat DJ, Karumbaiah L. 2019. Surfen-mediated blockade of extratumoral chondroitin sulfate glycosaminoglycans inhibits glioblastoma invasion. FASEB J 33:11973-11992. doi:10.1096/fj.201802610RR

Long KR, Huttner WB. 2019. How the extracellular matrix shapes neural development. Open Biol 9:180216. doi:10.1098/rsob.180216

Maekawa M, Yamamoto T, Kohno M, Takeichi M, Nishida E. 2007. Requirement for ERK MAP kinase in mouse preimplantation development. Development 134:2751-2759. doi: $10.1242 /$ dev.003756

Meloche S, Pouysségur J. 2007. The ERK1/2 mitogen-activated protein kinase pathway as a master regulator of the G1- to S-phase transition. Oncogene 26:3227-3239. doi:10.1038/sj.onc. 1210414

Minas TZ, Surdez D, Javaheri T, Tanaka M, Howarth M, Kang H, Han J, Han Z, Kream BE, Hong S, Çelik H, Tirode F. 2017. Combined experience of six independent laboratories attempting to create an Ewing sarcoma mouse model. Oncotarget 8:34141-34163. doi:10.18632/oncotarget.9388

Mosimann C, Kaufman CK, Li P, Pugach EK, Tamplin OJ, Zon LI. 2011. Ubiquitous transgene expression and Cre-based recombination driven by the ubiquitin promoter in zebrafish. Development 138:169-177. doi:10.1242/dev.059345

Muhammad EMS, El-Badawi ZH, Kroosh SS, Noaman HH. 2012. Evaluation of some histochemical and immunohistochemical criteria of round cell tumors of bone. Arab Soc Med Res 7:1687-4293. doi:10.7123/01.JASMR.0000414807.06421.47

Multhaupt HAB, Leitinger B, Gullberg D, Couchman JR. 2016. Extracellular matrix component signaling in cancer. Adv Drug Deliv Rev 97:28-40. doi:10.1016/j.addr.2015.10.013 
Mythreye K, Blobe G. 2009. Proteoglycan Signaling Co-receptors: Roles in Cell Adhesion, Migration and Invasion. Cell Signal 21:1548-1558. doi:10.1016/j.cellsig.2009.05.001

Naini SMA, Soussi-Yanicostas N. 2018. Heparan sulfate as a therapeutic target in tauopathies: Insights from zebrafish. Front Cell Dev Biol 6:163. doi:10.3389/fcell.2018.00163

Papy-Garcia D, Albanese P. 2017. Heparan sulfate proteoglycans as key regulators of the mesenchymal niche of hematopoietic stem cells. Glycoconj J 34:377-391. doi:10.1007/s10719-017-9773-8

Provost E, Rhee J, Steven L. 2007. Viral 2A Peptides Allow Expression of Multiple Proteins From a Single ORF in Transgenic Zebrafish Embryos. Genesis 45:625-629. doi:10.1002/dvg.20338

Riggi N, Suvà ML, Stamenkovic I. 2021. Ewing's Sarcoma. N Engl J Med 384:154-164. doi:10.1056/NEJMra2028910

Schuksz M, Fuster MM, Brown JR, Crawford BE, Ditto DP, Lawrence R, Glass CA, Wang L, Tor Y, Esko JD. 2008. Surfen, a small molecule antagonist of heparan sulfate. Proc Natl Acad Sci U S A 105:13075-13080. doi:10.1073/pnas.0805862105

Scotlandi K, Manara MC, Serra M, Marino MT, Ventura S, Garofalo C, Alberghini M, Magagnoli G, Ferrari S, Lopez-Guerrero JA, Llombard-Bosch A, Picci P. 2011. Expression of insulin-like growth factor system components in Ewing's sarcoma and their association with survival. Eur J Cancer 47:1258-1266. doi:10.1016/j.ejca.2011.01.007

Shafat I, Ben-Arush MW, Issakov J, Meller I, Naroditsky I, Tortoreto M, Cassinelli G, Lanzi C, Pisano C, Ilan N, Vlodavsky I, Zunino F. 2011. Pre-clinical and clinical significance of heparanase in Ewing's sarcoma. J Cell Mol Med 15:1857-1864. doi:10.1111/j.15824934.2010.01190.x

Silvany RE, Eliazer S, Wolff NC, Ilaria J. 2000. Interference with the constitutive activation of ERK1 and ERK2 impairs EWS/FLI-1-dependent transformation. Oncogene 19:4523-4530. doi:10.1038/sj.onc.1203811

Steinmetz R, Wagoner HA, Zeng P, Hammond JR, Hannon TS, Meyers JL, Pescovitz OH. 2004. Mechanisms regulating the constitutive activation of the extracellular signal-regulated kinase (ERK) signaling pathway in ovarian cancer and the effect of ribonucleic acid interference for ERK1/2 on cancer cell proliferation. Mol Endocrinol 18:2570-2582. doi:10.1210/me.2004-0082

Subramanian A, Tamayo P, Mootha VK, Mukherjee S, Ebert BL, Gillette MA, Paulovich A, Pomeroy SL, Golub TR, Lander ES, Mesirov JP. 2005. Gene set enrichment analysis: A knowledge-based approach for interpreting genome-wide expression profiles. Proc Natl Acad Sci U S A 102:15545-15550. doi:10.1073/pnas.0506580102

Suomi T, Seyednasrollah F, Jaakkola MK, Faux T, Elo L. 2017. ROTS : An R package for reproducibility- optimized statistical testing 13:e1005562. doi:10.1371/journal.pcbi.1005562

Umber F, Stoerring F, Foellmer W. 1938. Erfolge mit einem neuartigen Depot Insulin ohne Protaminzusatz (Surfen-Insulin). Klin Wochenschr 443-446.

Van De Luijtgaarden ACM, Versleijen-Jonkers YMH, Roeffen MHS, Schreuder HWB, Flucke UE, Van Der Graaf WTA. 2013. Prognostic and therapeutic relevance of the IGF pathway in Ewing's sarcoma patients. Target Oncol 8:253-260. doi:10.1007/s11523-012-0248-3 
772 Verduzco D, Amatruda J. 2011. Analysis of Cell Proliferation, Senescence and Cell Death in

773 Zebrafish Embryos. Methods Cell Biol 101:19-38. doi:10.1016/B978-0-12-387036-

$774 \quad 0.00002-5$

775 Wong KL, Akiyama R, Bessho Y, Matsui T. 2019. ERK activity dynamics during zebrafish

776 embryonic development. Int J Mol Sci 20. doi:10.3390/IJMS20010109

777 Yang C, Wang M, Zhou J, Chi Q. 2021. MicroRNA-335 targets the MEK/ERK pathway to

778 regulate the proliferation and metastasis of colon cancer. Am J Transl Res 12:7899-7907.

779 Yaylaci SU, Sen M, Bulut O, Arslan E, Guler MO, Tekinay AB. 2016. Chondrogenic

780 Differentiation of Mesenchymal Stem Cells on Glycosaminoglycan-Mimetic Peptide

$781 \quad$ Nanofibers. ACS Biomater Sci Eng 2:871-878. doi:10.1021/acsbiomaterials.6b00099

782 Zhou G, Yang J, Song P. 2019. Correlation of ERK/MAPK signaling pathway with proliferation

783 and apoptosis of colon cancer cells. Oncol Lett 17:2266-2270. doi:10.3892/ol.2018.9857 
Figure 1. Cre-inducible expression of EWSR1-FLI1 drives SRBCT development in integrate human EWSR1-FLII into the wild type zebrafish genome by microinjection into singlecell stage embryos. GFP-positive fish were monitored up to 4 months. B, Constructs for Creinducible expression of EWSRI-FLII. C, Incidence of GFP + tumors detected in Ubi:RSGEWSR1-FLI1; Cre RNA ( $=77)$ injected zebrafish versus Ubi:RSG-EWSRI-FLI1; GFP RNA $(\mathrm{n}=142)$ and uninjected controls $(\mathrm{N}=150)$ in a wildtype genetic background. ( $\mathrm{p}<0.001$ by $\log$ rank test). D, Representative images of GFP-positive tumors in zebrafish (top panel) and H\&E staining of tumor sections (bottom panel): (I) SRBCT with diffuse skeletal muscle infiltration, (II) visceral SRBCT arising from fin dorsal radial bone. Scale bars, $100 \mu \mathrm{m}$. E, Percent tumor incidence at different anatomic sites.

Figure 2. Zebrafish tumors phenocopy human Ewing sarcoma. A, Representative image of Ewing sarcoma tumor in WT zebrafish. H\&E staining, IHC staining with anti-FLI1 and antiCD99 antibodies. Scale bars, $100 \mu \mathrm{m}$. B, PAS staining of zebrafish tumors. Scale bars, $50 \mu \mathrm{m}$. C, Relative expression of human EWSR 1-FLI and zebrafish nrObl in normal and tumor tissues. Error bars represent SEM, $N=3$, * indicates $\mathrm{p}<0.05$, ** indicates $\mathrm{p}<0.01$, two-tailed Student's ttest. D, Immunofluorescence staining of zebrafish tumor with anti-GFP and anti-FLI1 antibodies. Scale bars, $20 \mu \mathrm{m}$. E, Validation of EWSR1-FLII expression in tumors at different sites by immunoblotting. F, GSEA comparing the enrichment of common upregulated proteins at dorsal, caudal and pectoral fin tumors to human Ewing sarcoma (GSE17674) and human Rhabdomyosarcoma (GSE108022) datasets.

Figure 3. Validation of EWSR1-FLI expression in zebrafish embryos. A, Timeline of zebrafish development after injection with $u b i$ RSG-EWSR1-FL plus Cre_mRNA (top panel). Zebrafish injected with $u b i$ :RSG-EWSRl-FLII plus GFP mRNA (middle panel) or $u b i$ :RSG plus Cre mRNA (bottom panel) were used as negative controls. Images were taken at 12hpf, 24hpf and 5dpf time points. B, Survival rate of embryos expressing EWSR 1-FLII during the first 10 days of development $(\mathrm{N}=524)$. Uninjected embryos $(\mathrm{N}=528)$ as well as embryos injected with $u b i$ :RSG-EWSR1-FLI1 plus GFP mRNA (N=328) or ubi:RSG plus Cre mRNA (N=304) were used as negative controls ( $\mathrm{p}<0.001$ by log-rank test). $\mathbf{C}$, Representative image of embryos with low (GFP+), medium (GFP++) and high (GFP+++) levels of EWSR1-FLI1 expression. D, Relative mRNA expression of EWSRl-FLI1 in embryos with low (GFP+), medium (GFP++) and high $(\mathrm{GFP}+++)$ levels of EWSR1-FLI1 according to GFP signal. E, Immunoblot confirming the expression of EWSR1-FLI1 protein in embryos with low (GFP+), medium (GFP++) and high Immunofluorescent staining of GFP (control) and GFP2A-EWSR1-FLII expressing embryos at 48hpf. Blue: phosphohistone H3. Green: GFP. A small region of the dorsal surface is shown. 

expressing embryos at 24hpf for pERK1/2 (red) and GFP. Scale bars, $100 \mu \mathrm{m}$. C, Immunofluorescent staining of GFP (control) and GFP2A-EWSR 1-FLI1 expressing embryos at $48 \mathrm{hpf}$ for pERK1/2 (Red), pH3 (blue) or GFP (green). Scale bars, $20 \mu \mathrm{m}$. D, Immunostaining of zebrafish tumor for $\mathrm{pERK} 1 / 2$. E, Immunoblot analysis of $\mathrm{pERK} 1 / 2$ and ERK1/2 levels in tumor and normal tissue. F, Quantification of immunoblot Error bars represent SEM, N=3, * indicates $\mathrm{p}<0.05$, two-tailed Student's t-test.

Figure 5. LC-MS/MS analysis of proteins affected by EWSR1-FLI1 expression in developing zebrafish. A, Heat map representing the differentially expressed proteins dysregulated by EWSR1-FLI1 at 24hpf and 48hpf. B, Quantitative analysis of the differentially expressed proteins at $24 \mathrm{hpf}$ and $48 \mathrm{hpf}$. C, D, Gene ontology (GO) analysis of differentially expressed proteins at $48 \mathrm{hpf}$. E, Volcano plot of significantly downregulated and upregulated proteins in EWSRI-FLII expressing embryos. F, Heatmap of the most differentially expressed proteins involved in proteoglycan metabolism in human Ewing sarcoma compared to normal tissue (GSE17674).

Figure 6. Surfen treatment impairs ERK1/2 signaling and growth of Ewing sarcoma cells. A, Immunoblot analysis of pERK1/2, ERK1/2 and tubulin levels in TC32 and EWS502 cells treated with surfen or DMSO. B, Immunoblot quantification of pERK1/2 expression level relative to ERK1/2 in TC32 and EWS502 cells treated with surfen or DMSO vehicle control. Error bars represent SEM, N=3, * indicates $\mathrm{p}<0.05$, ** indicates $\mathrm{p}<0.01$, based on one-way ANOVA test. C, Proliferation rates of TC32 and EWS502 cells treated with surfen or DMSO. Error bars represent SEM, N=3, ** indicates $\mathrm{p}<0.01$, *** indicates $\mathrm{p}<0.001$, **** indicates $\mathrm{p}<0.0001$ based on one-way ANOVA test. D, Morphological changes in TC32 and EWS502 cells after surfen or DMSO treatment. D, Clonogenic assay of TC32 and EWS502 cells treated with Surfen or DMSO. Error bars represent SEM, N=4, *** indicates $\mathrm{p}<0.001$, **** indicates $\mathrm{p}<0.0001$ based on one-way ANOVA test.

Figure 7. Surfen inhibits EWSR1-FLI1 mediated growth in the zebrafish model. A, Surfen inhibits the development of EWSRI-FLI1 driven outgrowths in zebrafish larvae. B, Changes in the fin shape driven by EWSRI-FLII expression. Embryos injected with ubi:RSG-EWSRl-FLII plus GFP mRNA were used as control. C, Scheme of surfen treatment. Wild type embryos were used for the integration of EWSR1-FLI1 into the zebrafish genome. Uninjected fish were used as control. GFP positive embryos were treated with surfen at $2 \mu \mathrm{M}$ or $2 \%$ DMSO vehicle control. Zebrafish were imaged after 48 hours of treatment. Coefficient of curvature was calculated as following Ccurv=(L1-L0)/L0*100, where L1 is the length of fin edge between points A and B and LO is the length of the straight line between those two points. D, Fins representing different coefficients of curvature Ccurv caused by EWSR1-FLII expression. E, Treatment of fish expressing EWSR1-FLI1 with surfen leads to the rescue of fin curvature phenotype. Error bars represent SEM, biological replicates $\mathrm{N}=4$, ** indicates $\mathrm{p}<0.01$, *** indicates $\mathrm{p}<0.001$, **** 


\section{Supplemental Materials}

\section{Supplemental Figure Legends}

Supplemental Figure 1, referring to Figure 1. The Tol2 transposon-based system was used to integrate EWSRI-FLII into the zebrafish genome by microinjection into single-cell stage zebrafish embryos. A, Scheme of constructs for expression of EWSR1-FLI1 under cmv, fli1, mitfa, ubi promoters. B, Scheme of constructs for Cre-inducible expression of eGFP-2A-EWSR1FLII under $c m v$, flil, b-actin, ubi promoters.

Supplemental Figure 2, Referring to Figure 1. The Tol2 transposon-based system was used to integrate b-actin:RSG-EWSR1-FLI1 into the wild type zebrafish genome. Coinjection of Cre mRNA or GFP mRNA was used to generate EWSRI-FLIl expressing or control zebrafish, respectively. A, TUNEL assay (red) made on zebrafish expressing GFP (green) or GFP2AEWSR1-FLII (green) at 36hpf. B, Relative mRNA expression of EWSR1-FLI1 in b-actin:RSGEWSR1-FLI1 zebrafish injected with Cre RNA or GFP RNA. C, Expression of EWSR1-FLI1 on the protein level was confirmed by immunoblotting. $D$, Representative images of zebrafish expressing EWSR1-FLI1 driven by b-actin promoter at $1 \mathrm{mpf}$. E, H\&E staining of cell masses formed in the head of zebrafish expressing EWSR1-FLII under b-actin promoter (right) and control (left). Error bars represent SEM, $N=3$, **** indicates $\mathrm{p}<0.0001$, two-tailed Student's ttest.

Supplemental Figure 3, Referring to Figure 1. Mosaic model of Ewing sarcoma generated by the microinjection of $u b i: R S G-E W S R 1-F L I 1$ plus Cre mRNA into single-cell stage embryos. A, Plot representing the incidence of one, two, three or four tumors per zebrafish. B, EWSRI-FLI1 triggers the formation of ectopic fins in zebrafish. C, Examples of tumors observed in mosaic model of Ewing sarcoma.

Supplemental Figure 4, Referring to Figure 2. IHC staining of sections of zebrafish tumor and control zebrafish with anti-FLI1 antibodies. outgrowth at 72hpf for pERK1/2 (red), GFP2A-EWSR1-FLI1 (green). Arrows indicate cells positive for pERK1/2 and negative for EWSR1-FLI1. Scale bars, $20 \mu \mathrm{m}$. B, IHC staining of sections of zebrafish tumor and control zebrafish with anti-pERK1/2 antibodies. Scale bars, 100 $\mu \mathrm{m}$

906

\section{Supplemental Movie 1}

909 Immunofluorescence staining of a 48hpf zebrafish embryo for pERK1/2 (red), EWSR1-FLI1 
912 Immunofluorescence staining of a tumor outgrowth in 48hpf zebrafish embryo for pERK1/2

913 (red), EWSR1-FLI1 (green) and pH3 (blue). Confocal Z-stack focusing on an outgrowth arising

914 from the dorsal surface of the embryo.

915

916 Supplemental Table 1

917 Detailed characterization of zebrafish tumors driven by EWSR1-FLI1 expression

918

919 Supplemental Table 2

920 List of downregulated and upregulated proteins identified by LC-MS/MS analysis in EWSRl-

$921 \quad$ FLII expressing embryos, $p<0.05$

922

923 Supplemental Table 3

924 List of primers for RT-PCR 
bioRxiv preprint doi: https://doi.org/10.1101/2021.05.25.445683; this version posted May 27, 2021. The copyright holder for this preprint (which

was not certified by peer review) is the author/funder, who has granted bioRxiv a license to display the preprint in perpetuity. It is made available under aCC-BY 4.0 International license.

\section{Figure 1}

A

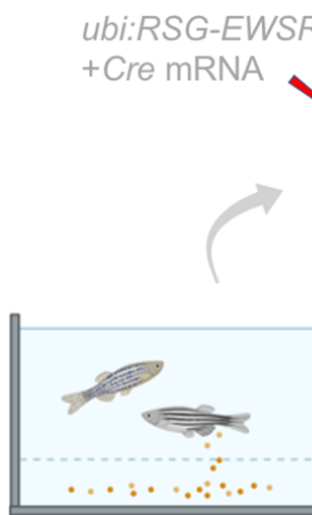

WT

B

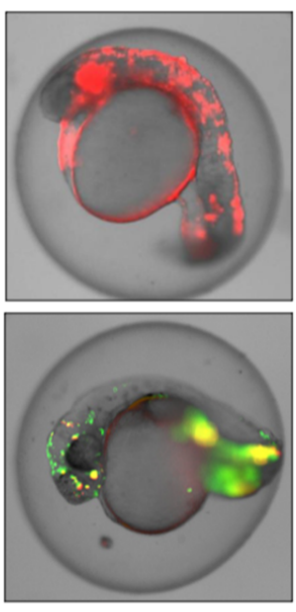

$24 \mathrm{hpf}$

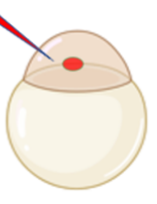

Cre-inducible zebrafish model of Ewing Sarcoma

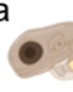

14-120 dpf

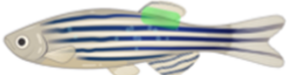

EWSR1-FLI1

driven tumors

-Cre
EWSR1-FLI driven tumor initiation

\section{2-14 dpf}

\section{progression}

+ Cre

Tol2 ubi: IoxP eGFP-2A EWSR1-FLI Tol2

D
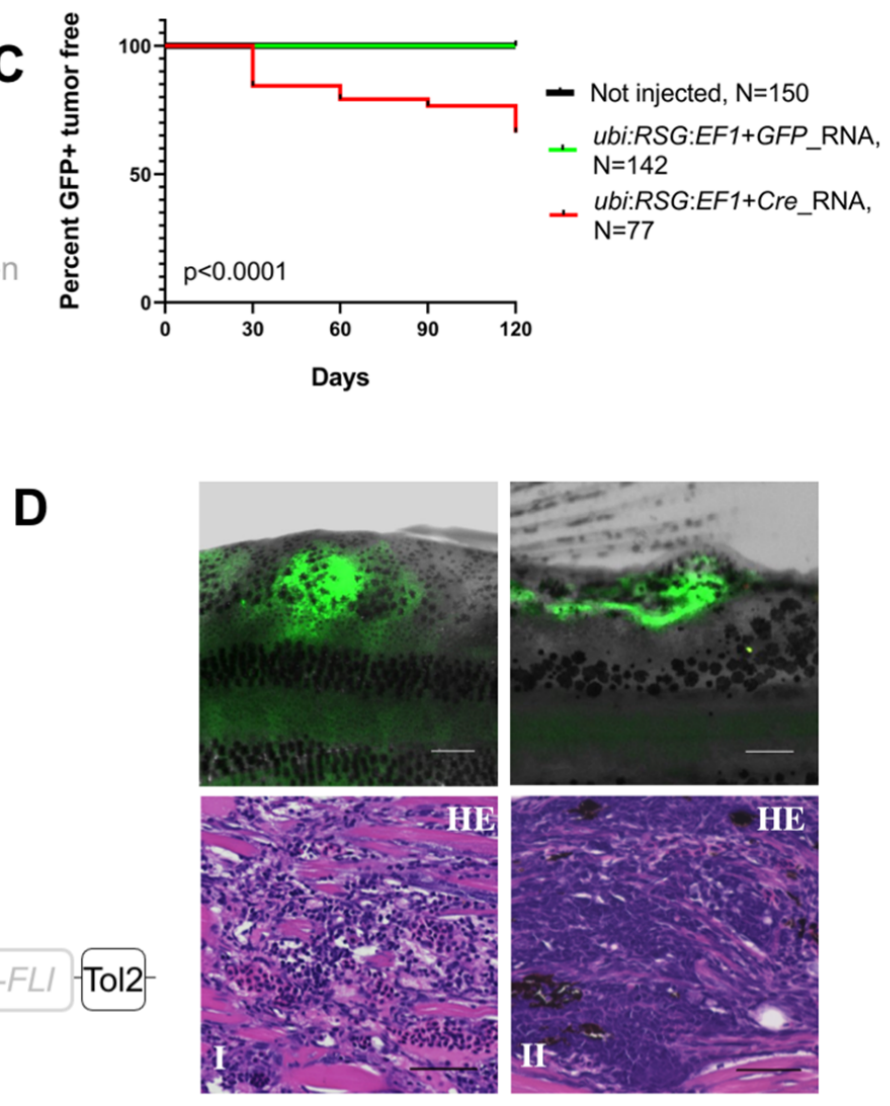

HE

$15 \%$

(I)

$37 \%$

(II)

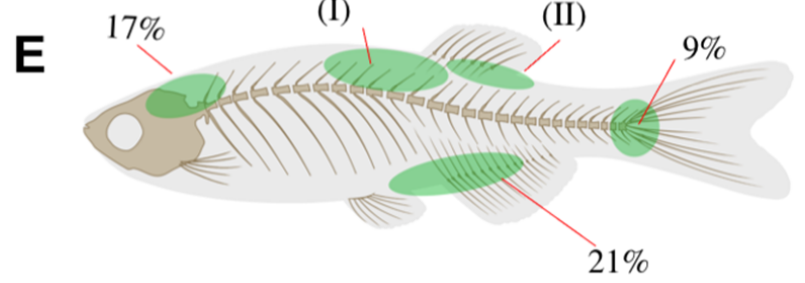




\section{Figure 2}

A
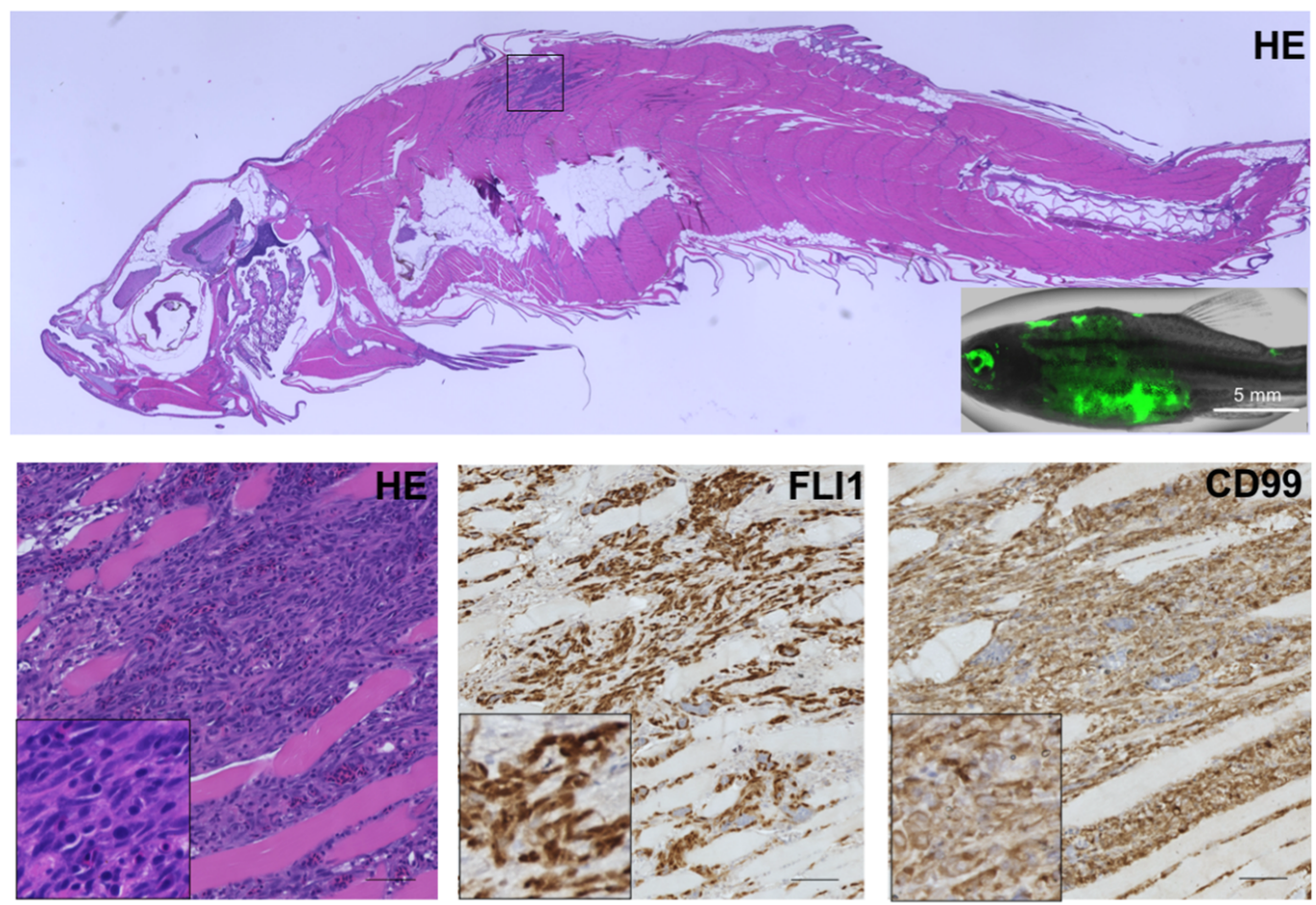

B

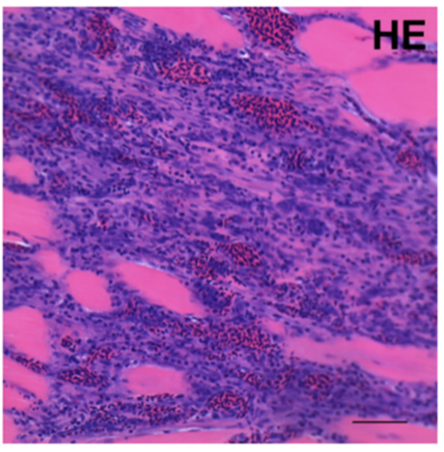

E

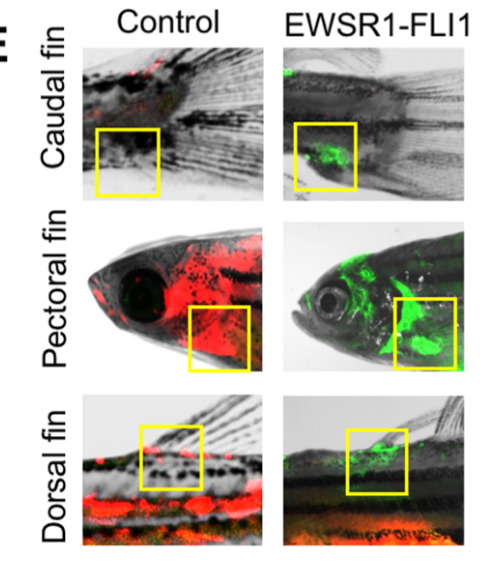

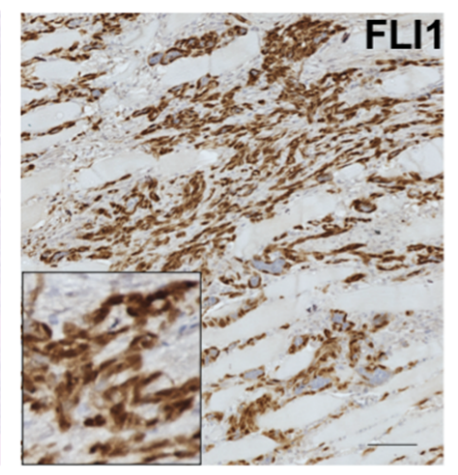
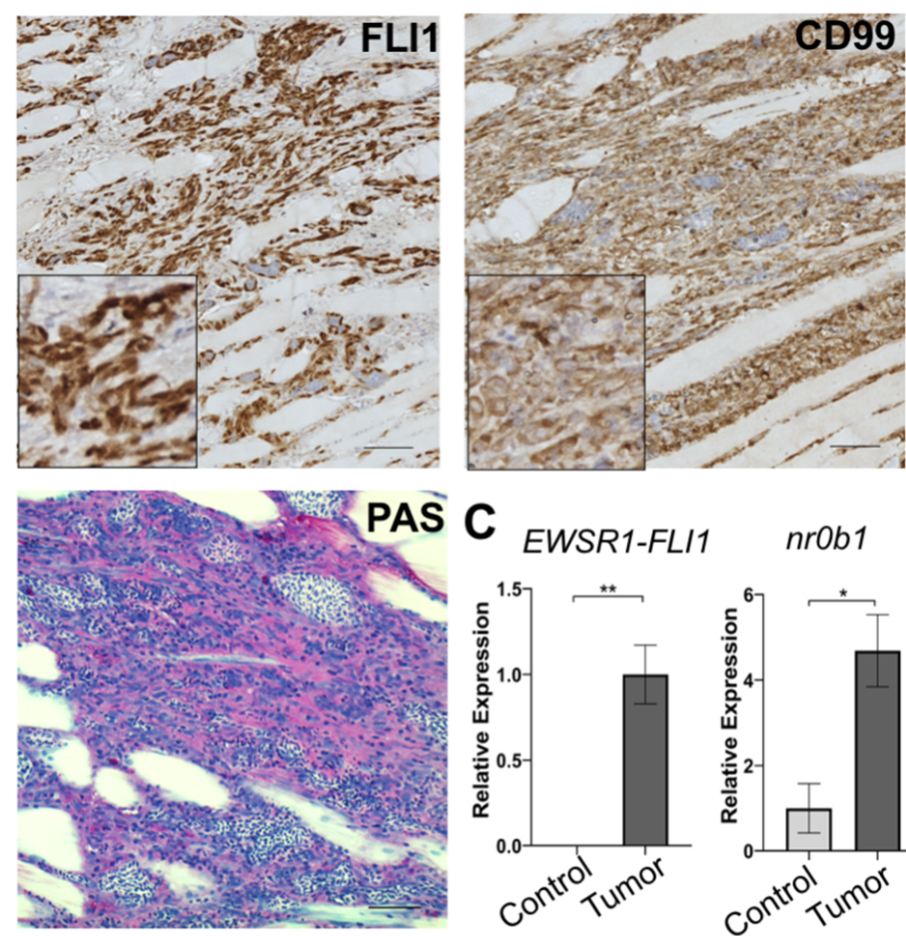

M.w.

kDa Ctrl EF1

$\begin{array}{ll}67- & -2 \\ 52- & \text { EWSR-FLI1 }\end{array}$

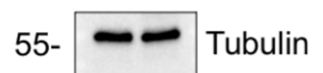

67- - EWSR-FLI1

52- $-\infty$ FLI1

55- - Tubulin

67- $=$ EWSR-FLI1

52- -- FLI1

55- $-\infty$ Tubulin

F $\quad \begin{aligned} & \text { vs human } \\ & \text { Ewing Sarcoma }\end{aligned}$
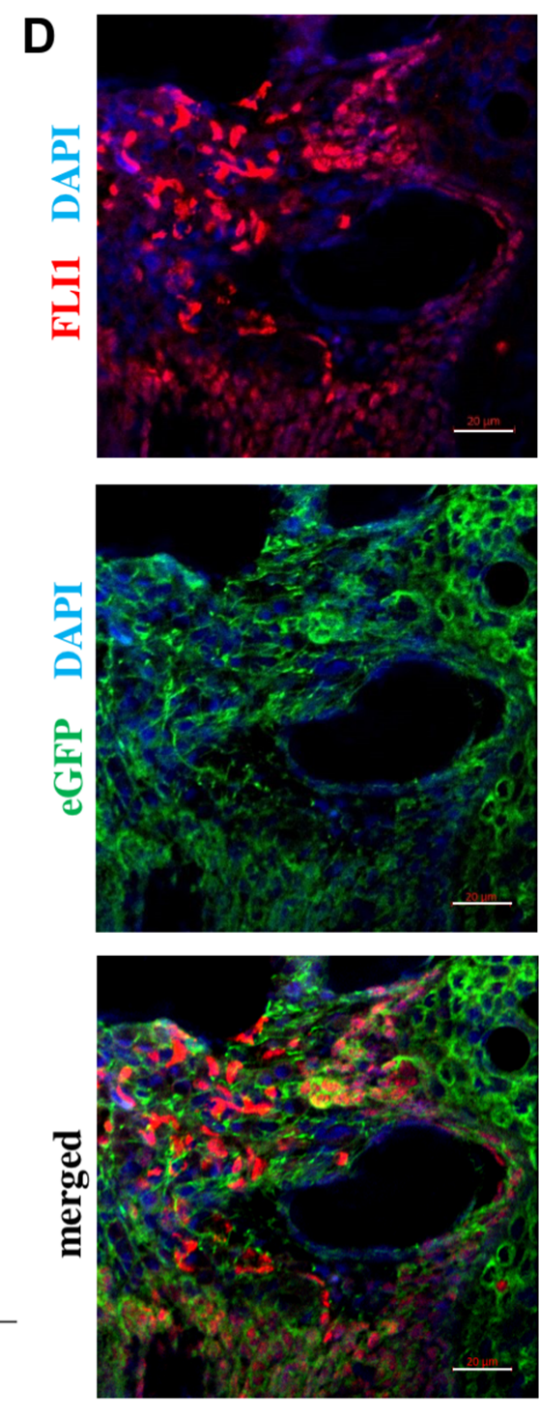

vs human

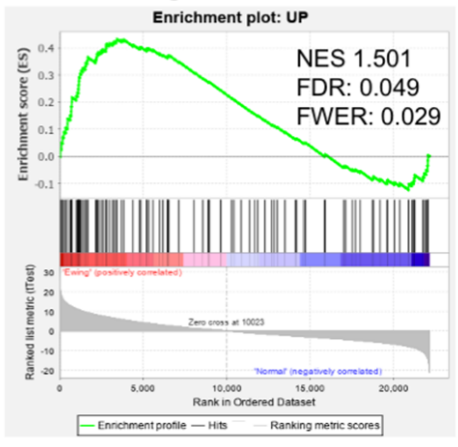

Rhabdomyosarcoma

Enrichment plot: UP

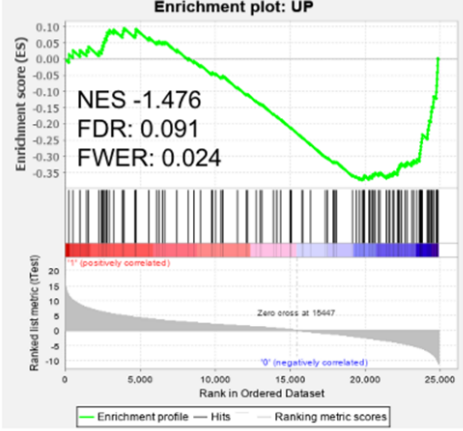




\section{Figure 3}

A

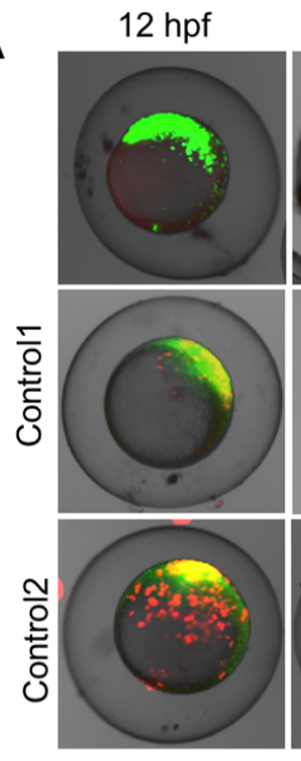

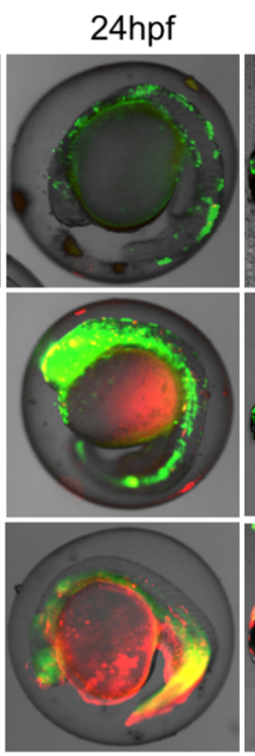
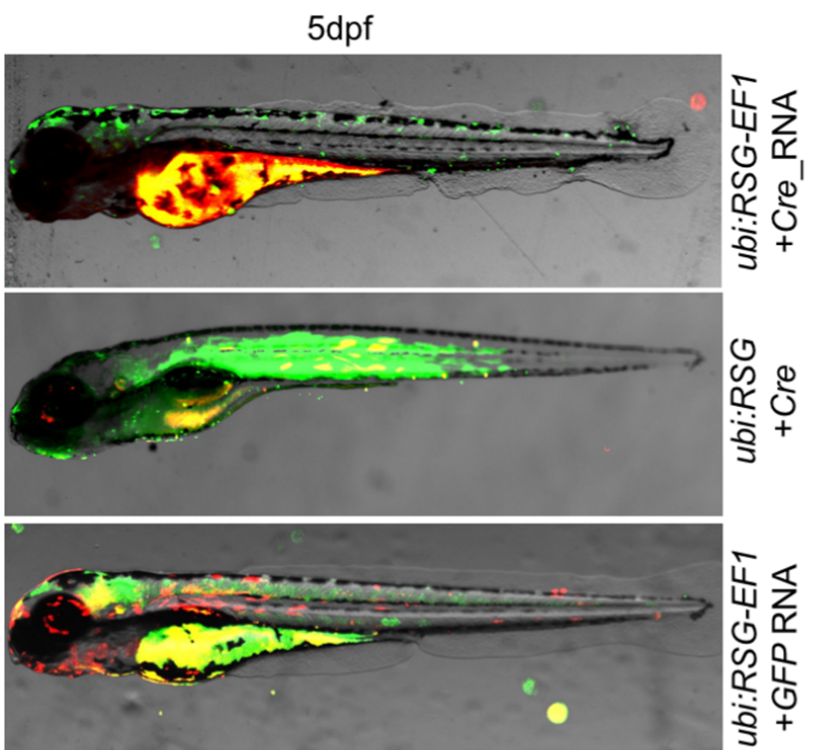

B

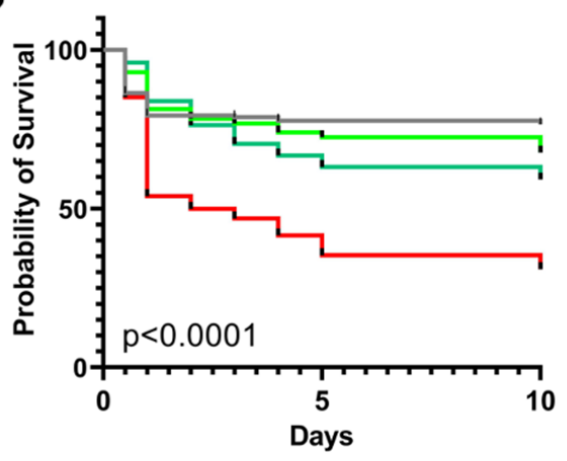

- Not injected, $\mathrm{N}=528$

- ubi:RSG:EF1+GFP_RNA, N=328

- ubi:RSG+Cre_RNA, N=304

- ubi:RSG:EF1+Cre_RNA, N=524

C

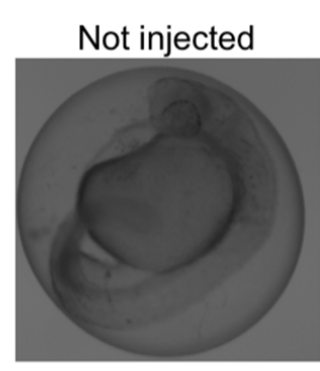

+Ubi-RSG+Cre

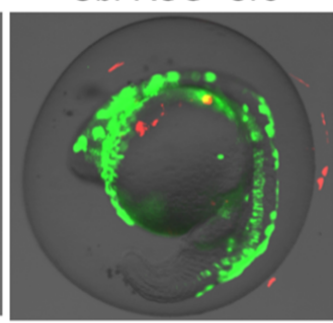

+GFP_RNA

ubi:RSG-EWSR1-FLI1

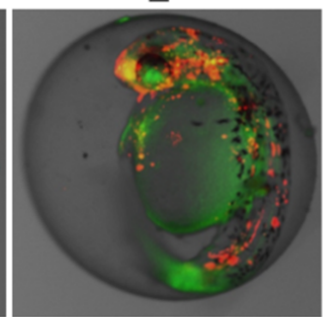

+Cre_RNA

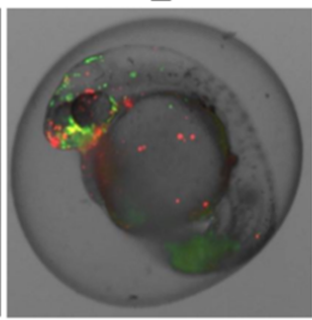

GFP+

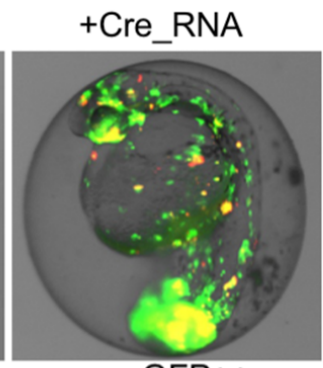

GFP++

\section{+Cre RNA}

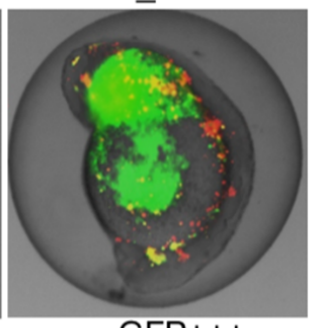

GFP+++
D

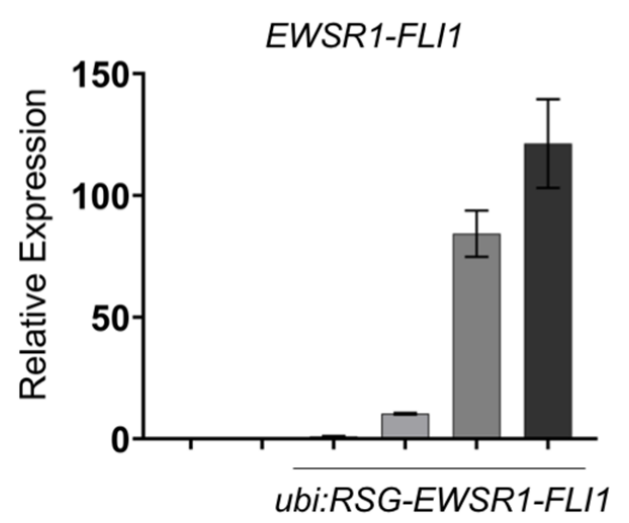

E

$\square$ Not injected

$\square$ ubi:RSG+Cre_RNA

$\square$ GFP_RNA

$\square$ Cre_RNA, GFP+

$\square$ Cre_RNA, GFP++

- Cre_RNA, GFP+++
M.w.

$\mathrm{kDa}$

67-

$57-$

$55-$

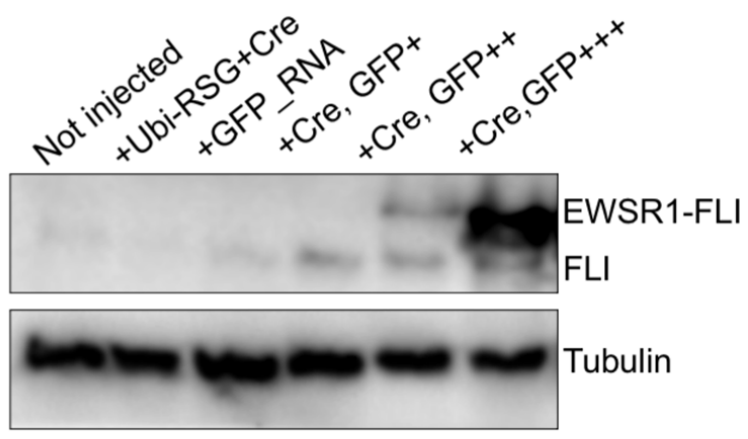

ubi:RSG-EWSR1-FLI1 
Finbioxiv preprint doi: https://doi.org/10.1101/2021.05.25.445683; this version posted May 27, 2021. The copyright holder for this preprint (which

Figure n 4 certified by peer review) is the author/funder, who has granted bioRxiv a license to display the preprint in perpetuity. It is made available under aCC-BY 4.0 International license.

A

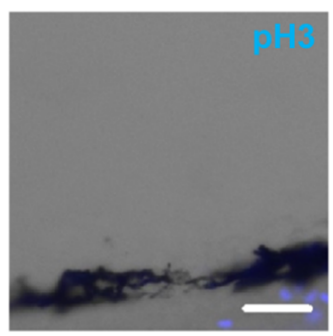

B
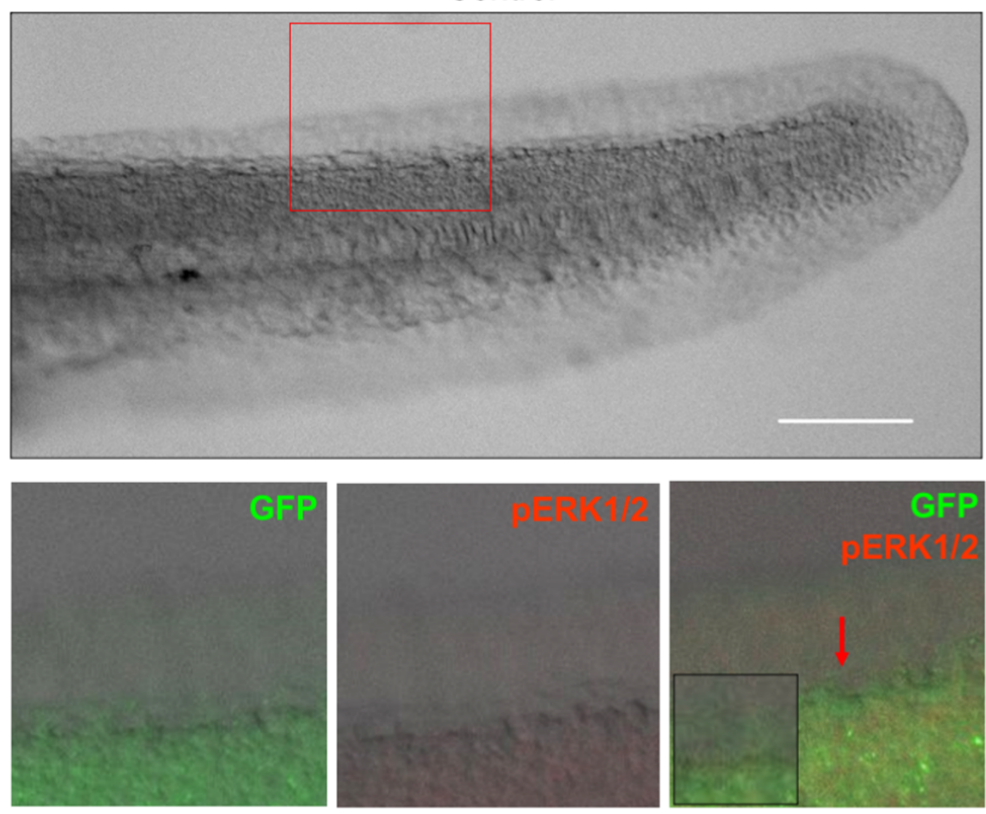

C

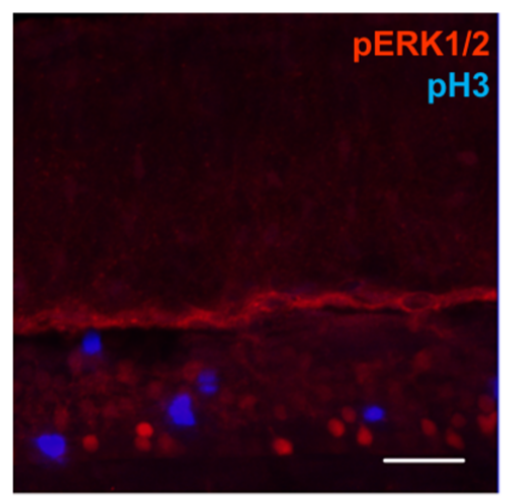

Control

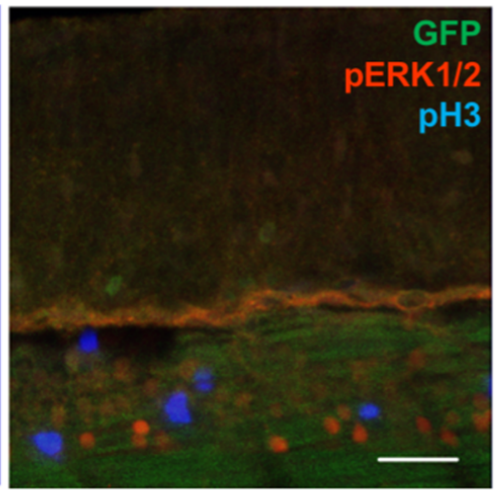

D
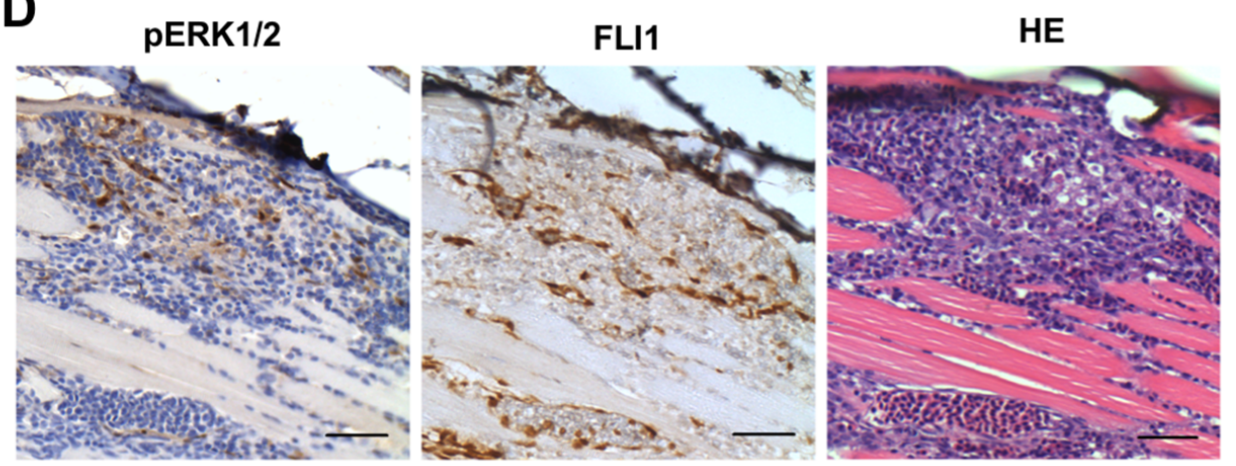

$\mathbf{E}$

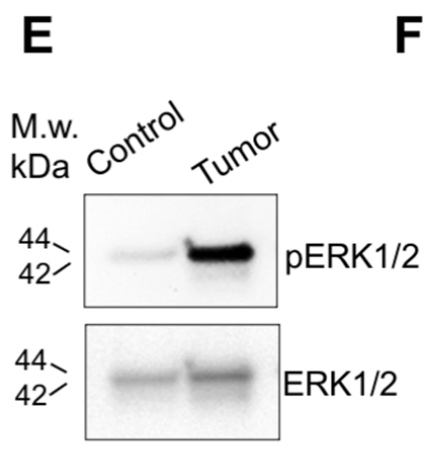

$\mathbf{F}$

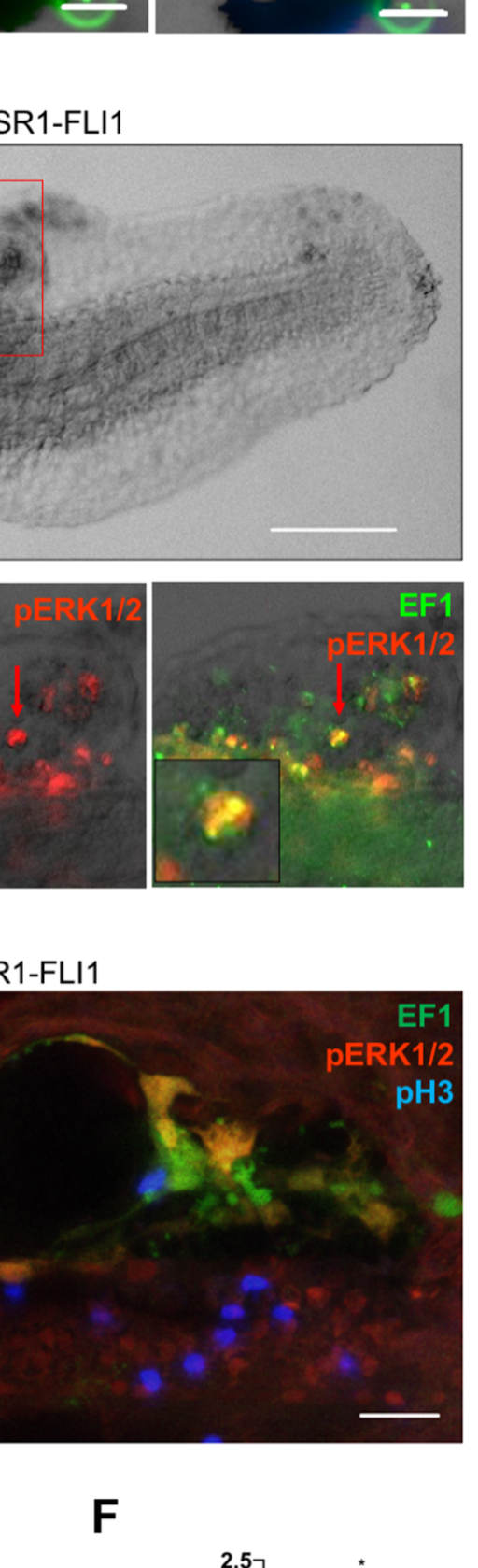

\section{EWSR1-FLI1}
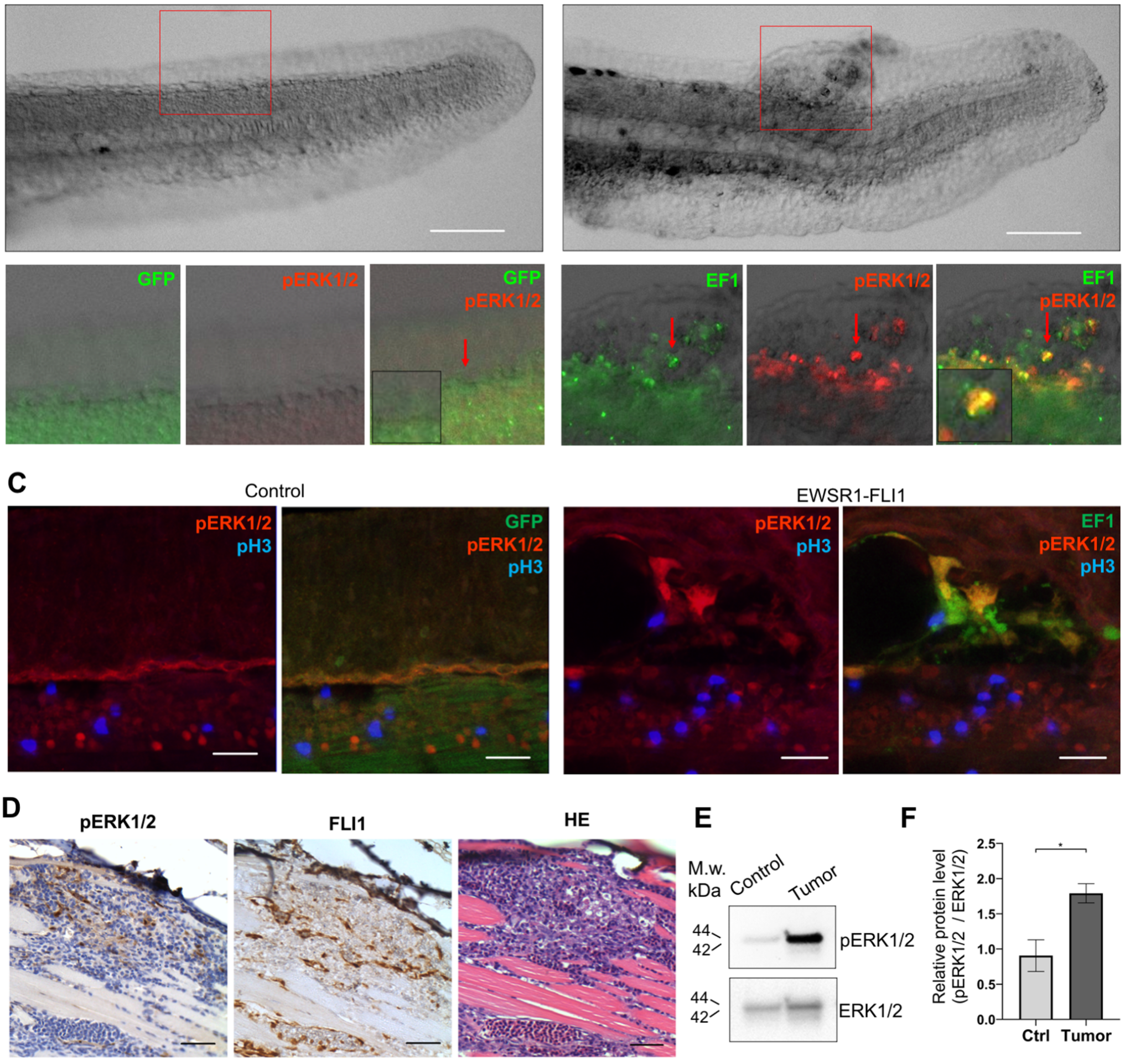
Ei bioRxiv preprint doi: https://doi.org/10.1101/2021.05.25.445683; this version posted May 27, 2021. The copyright holder for this preprint (which - IgU 1 S $\mathrm{n}$ certified by peer review) is the author/funder, who has granted bioRxiv a license to display the preprint in perpetuity. It is made available under aCC-BY 4.0 International license.

A
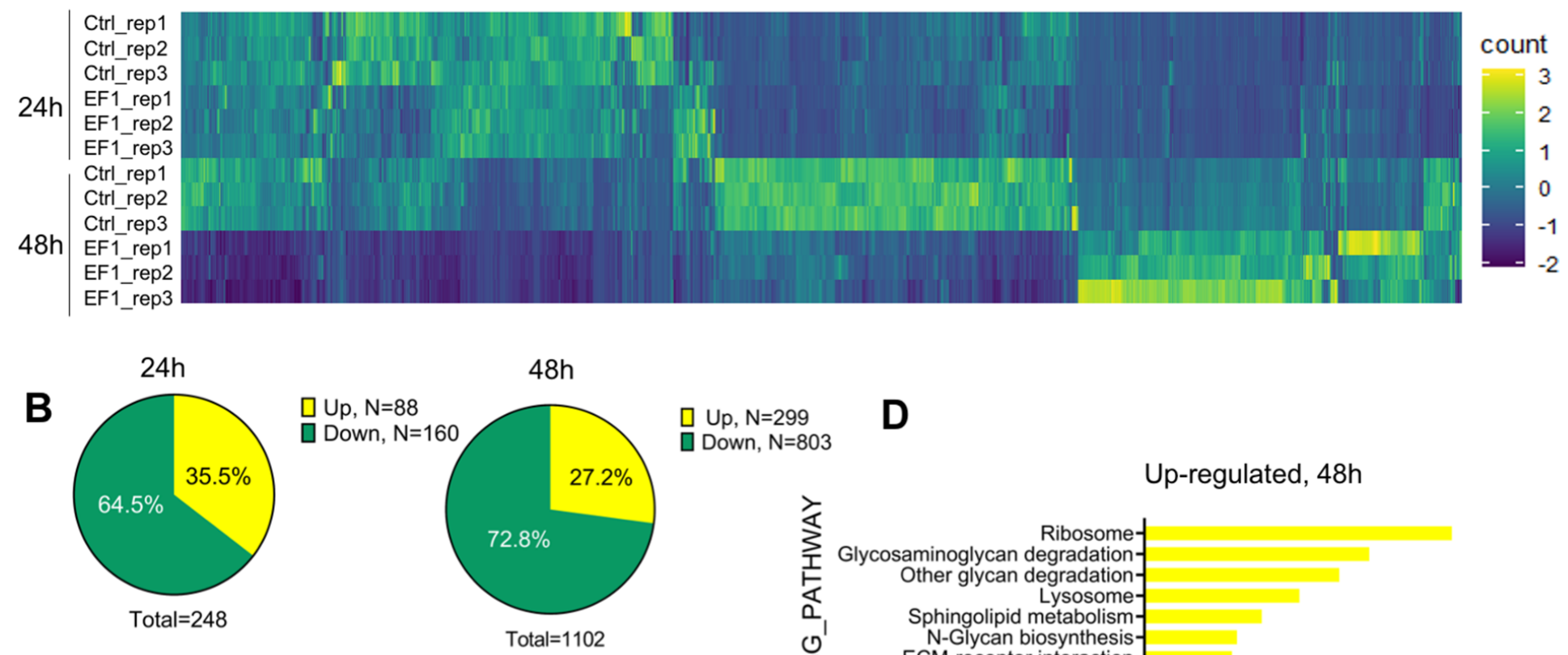

C

Down-regulated, $48 \mathrm{~h}$

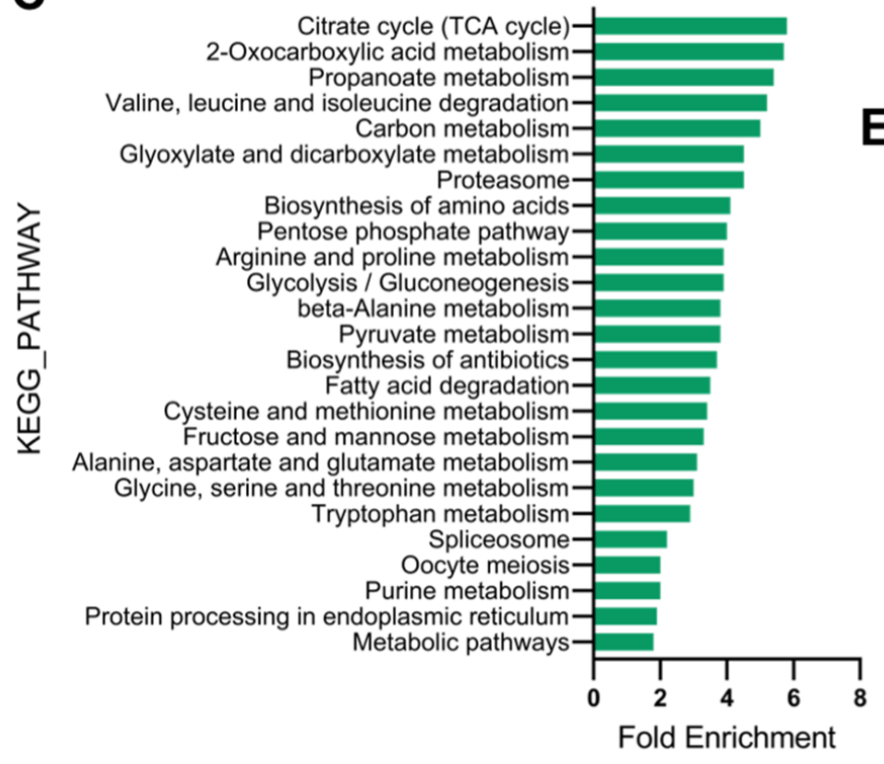

$\begin{aligned} & \text { Up, } \mathrm{N}=299 \\ & \text { Down, } \mathrm{N}=803\end{aligned}$
D

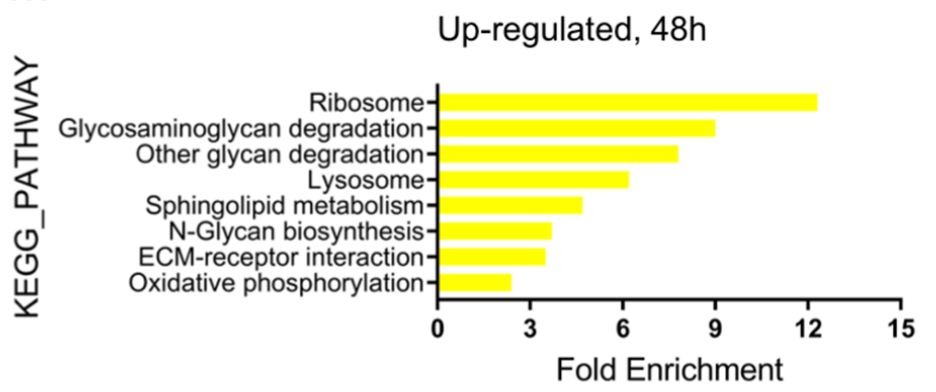

E

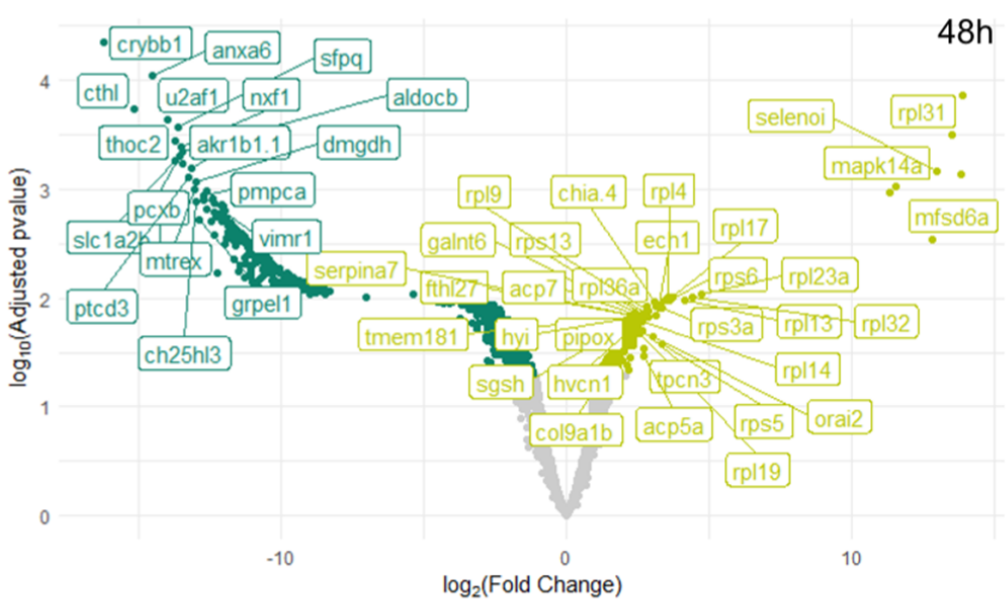

$\mathbf{F}$
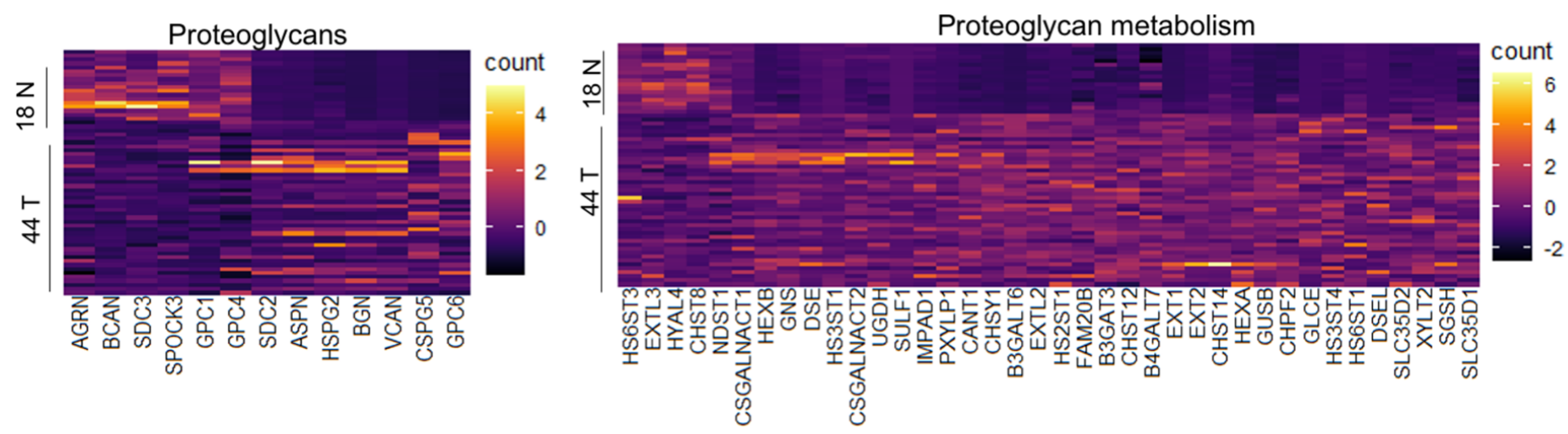


\section{Figure 6}

A

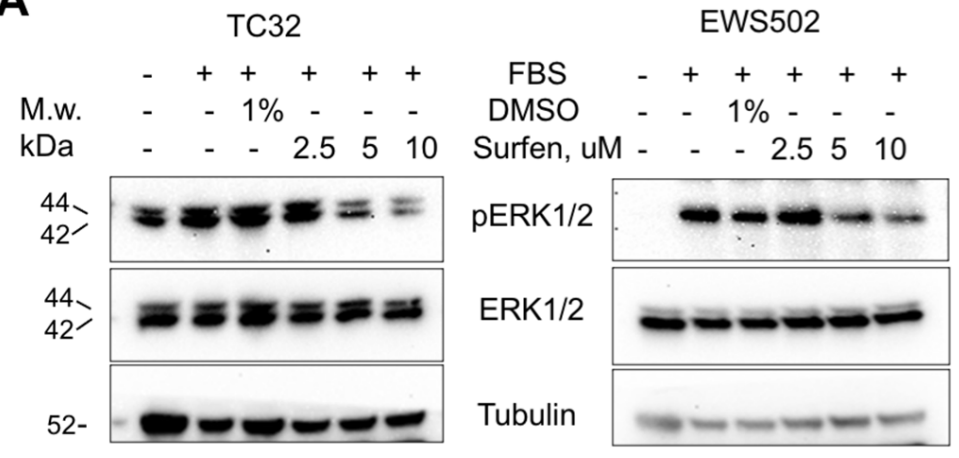

C
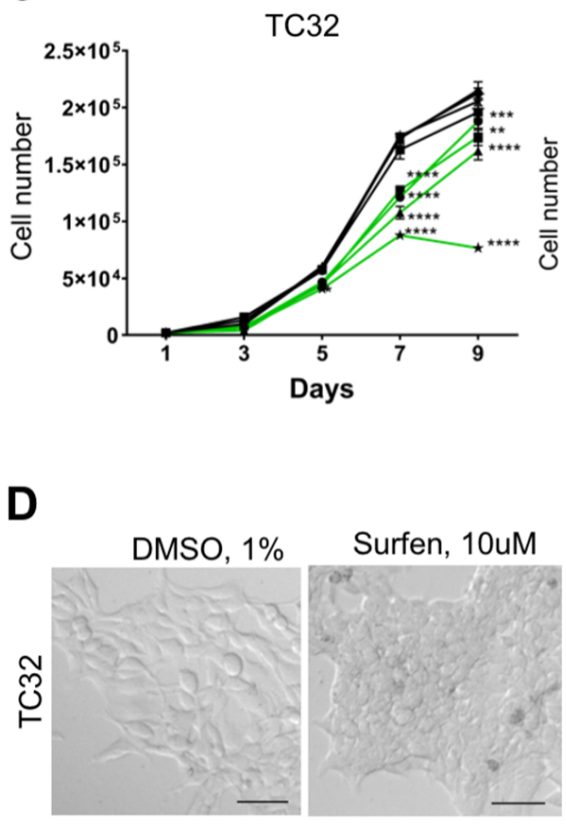

B

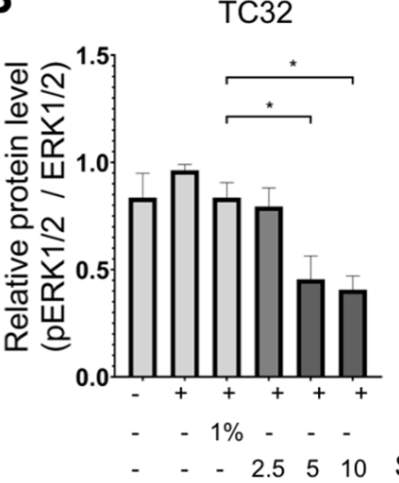

$\mathbf{E}$

EWS502

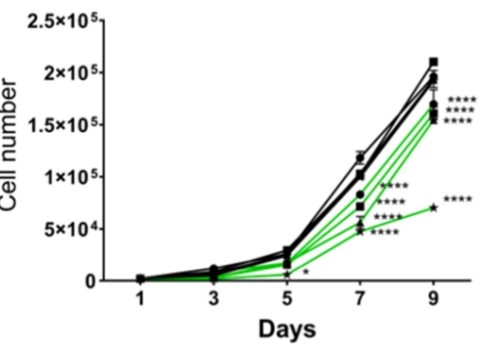

- DMS0 $0.025 \%$

DMSO $0.05 \%$

DMSO $0.1 \%$

* DMSO $0.2 \%$

- Surfen 1.25uM

- Surfen 2.5 uM

- Surfen 5 uM

* Surfen $10 \mathrm{um}$
EWS502

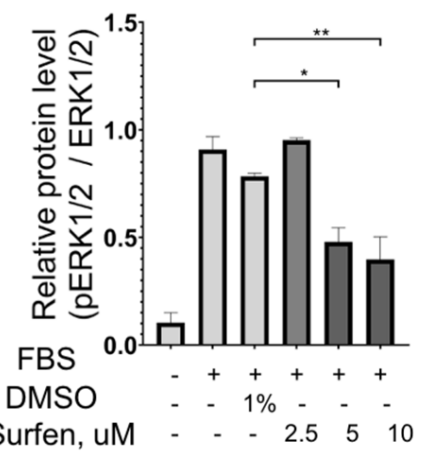

TC32

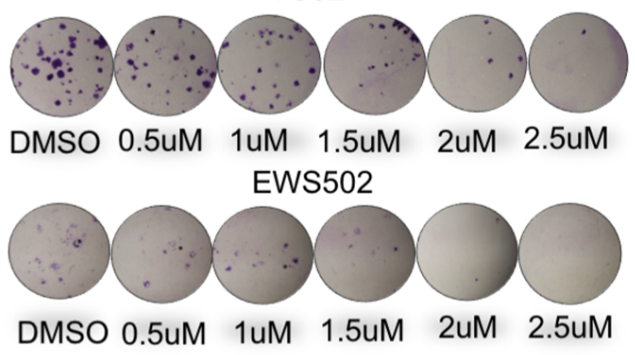

EWS502

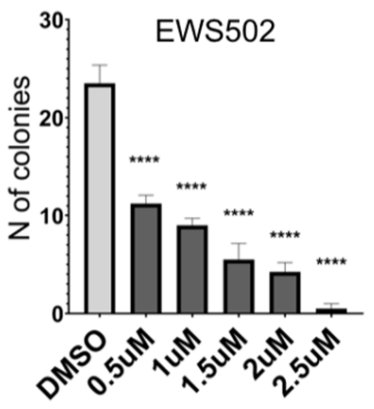




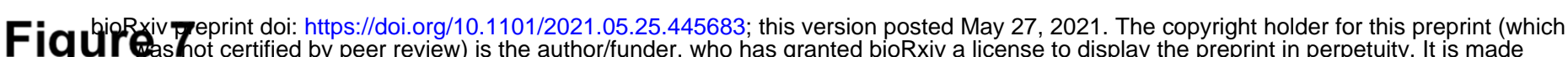
Figureashot certified by peer review) is the author/funder, who has granted bioRxiv a license to display the preprint in perpetuity. It is made available under aCC-BY 4.0 International license.

+Surfen

+ DMSO

A
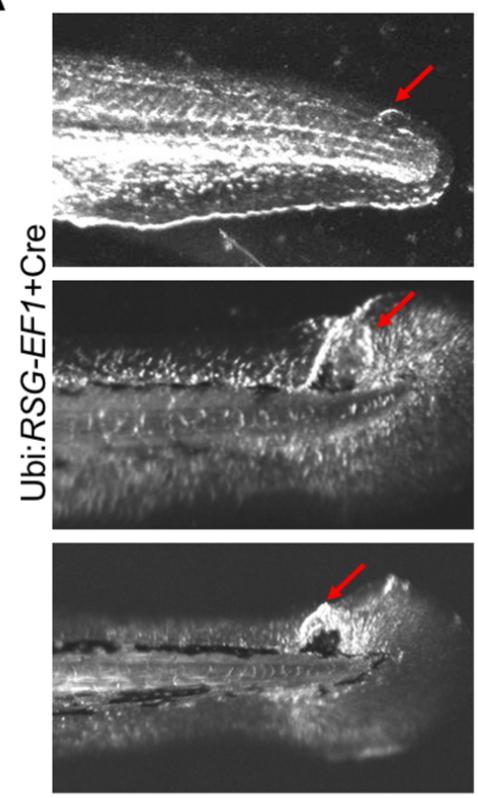

$\mathrm{Oh}$
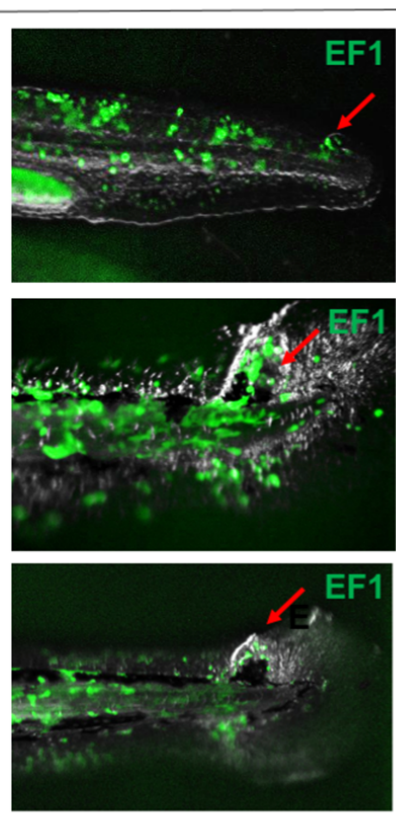

B

Control
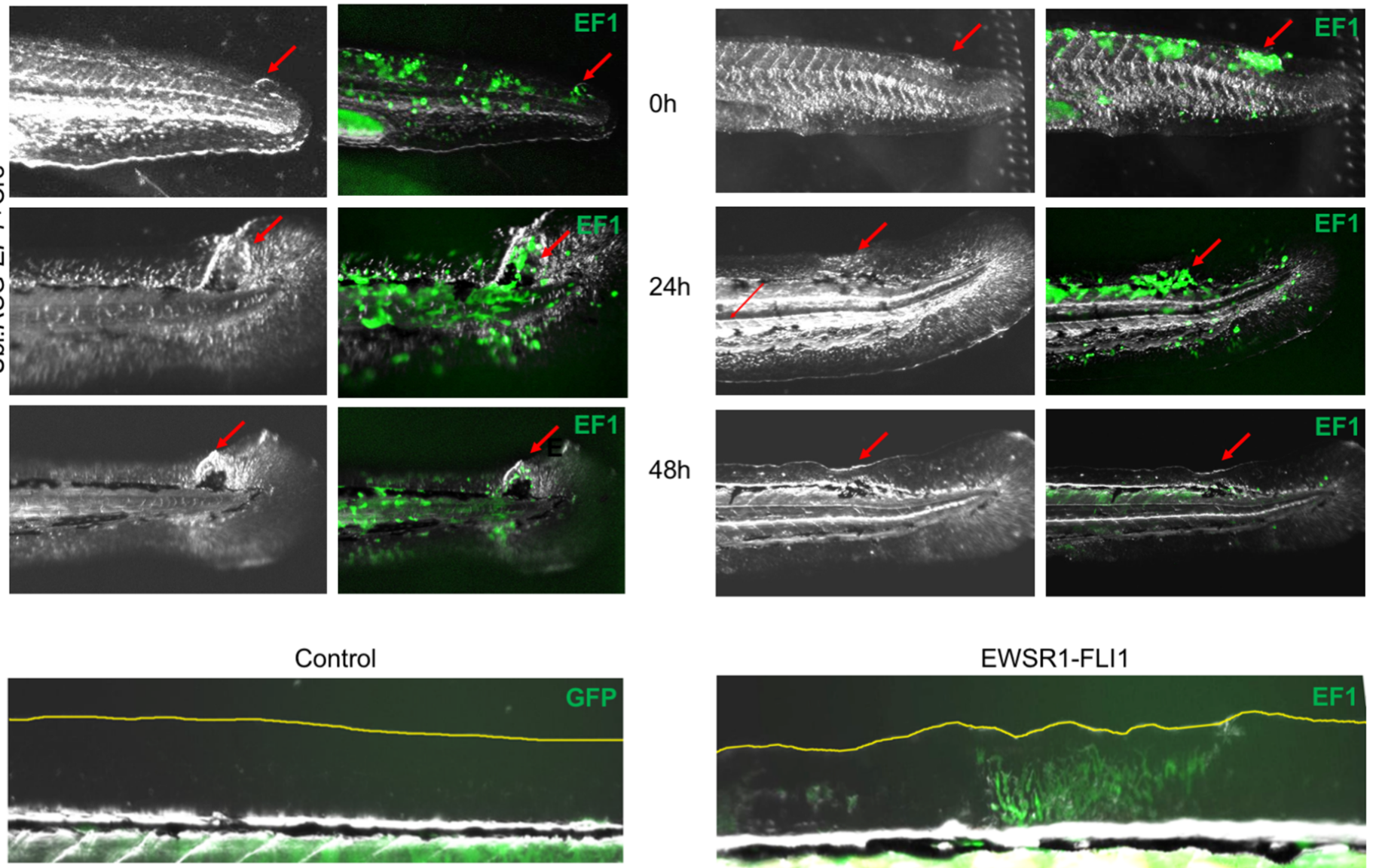

$48 \mathrm{~h}$
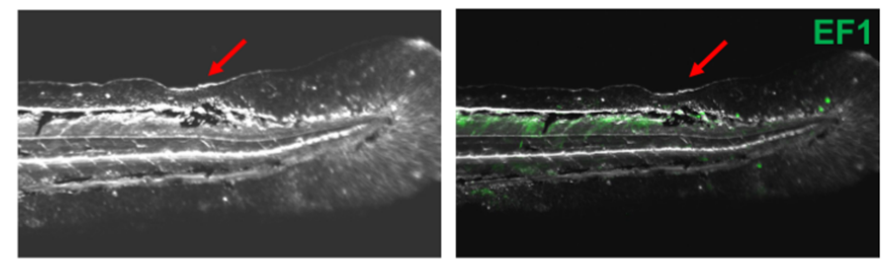

\section{EWSR1-FLI1}

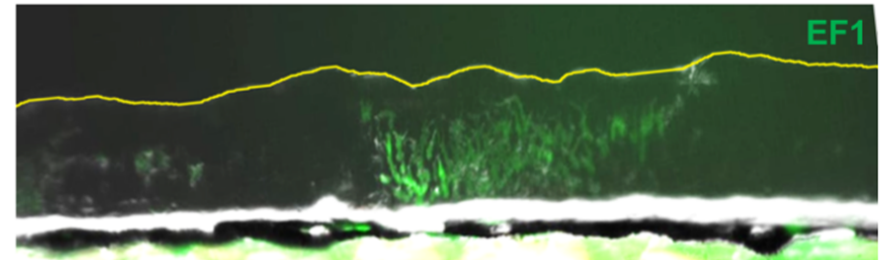

c

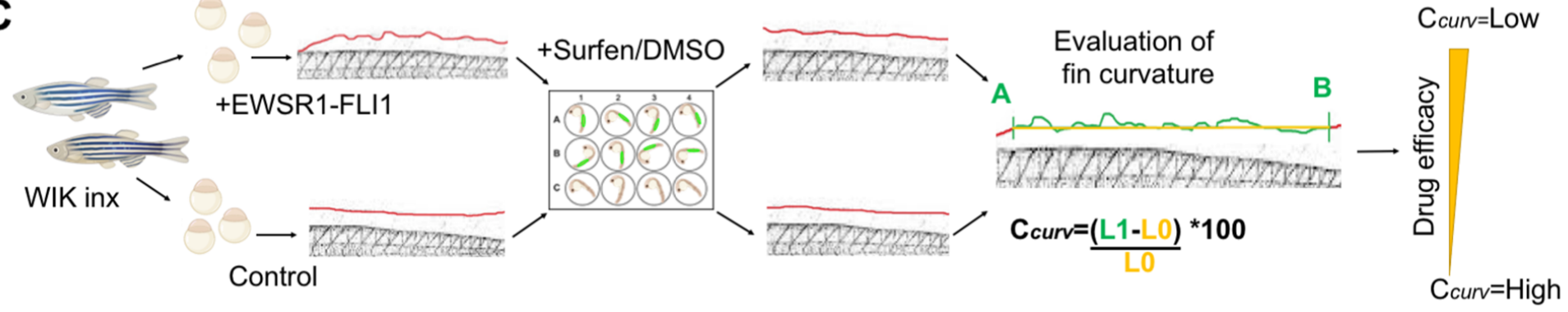

D

\section{$\mathrm{C}_{\text {curv }}=7.01$}

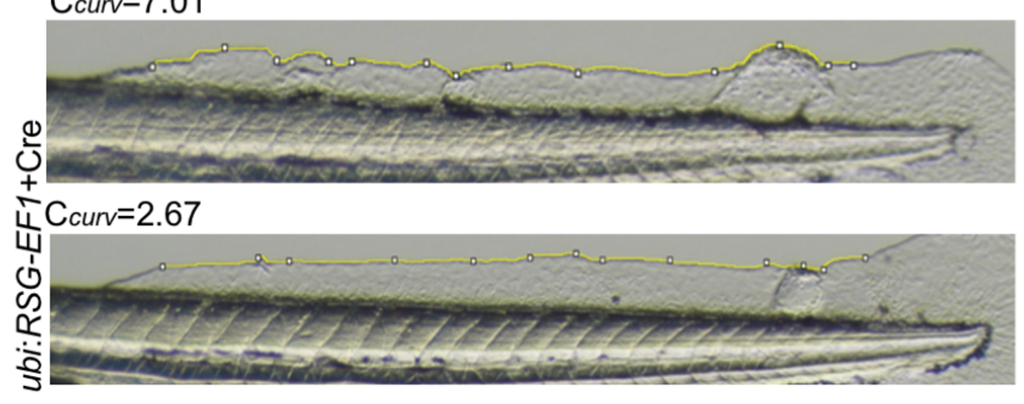

$\mathrm{C}_{\text {curv }}=1.17$
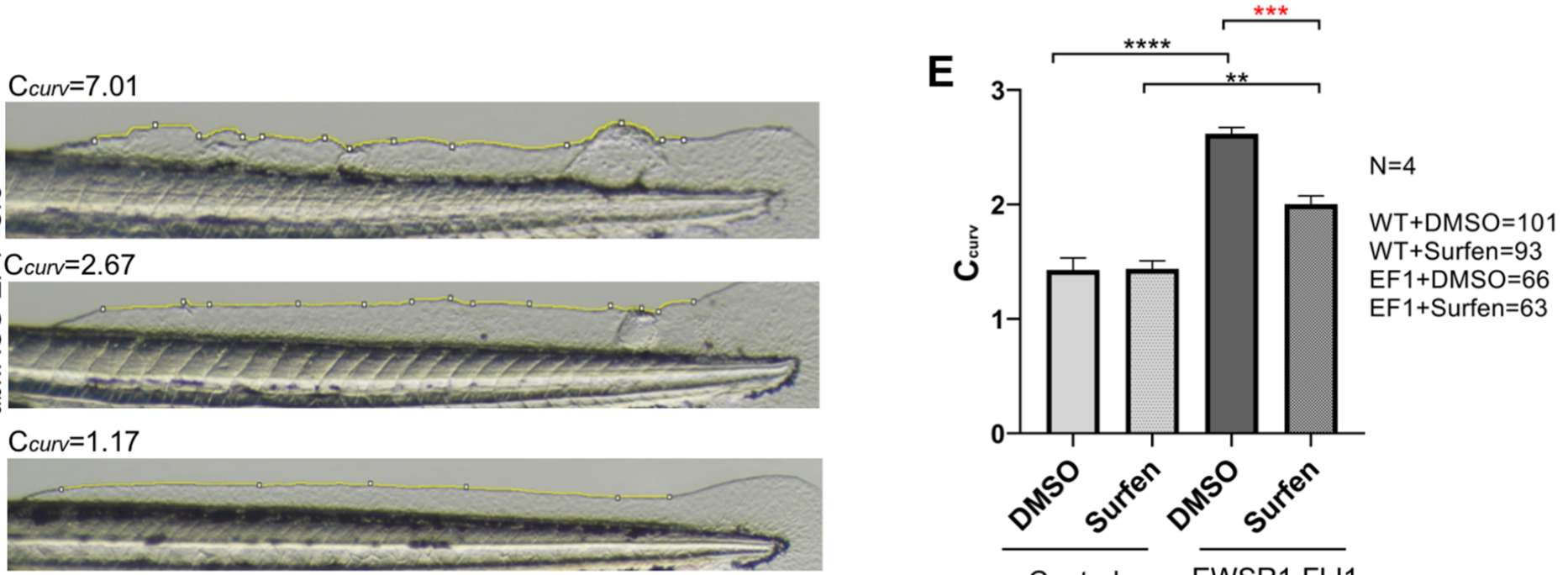
bioRxiv preprint doi: https://doi.org/10.1101/2021.05.25.445683; this version posted May 27, 2021. The copyright holder for this preprint (which

was not certified by peer review) is the author/funder, who has granted bioRxiv a license to display the preprint in perpetuity. It is made available under aCC-BY 4.0 International license.

\section{Sup. Figure 1}

A
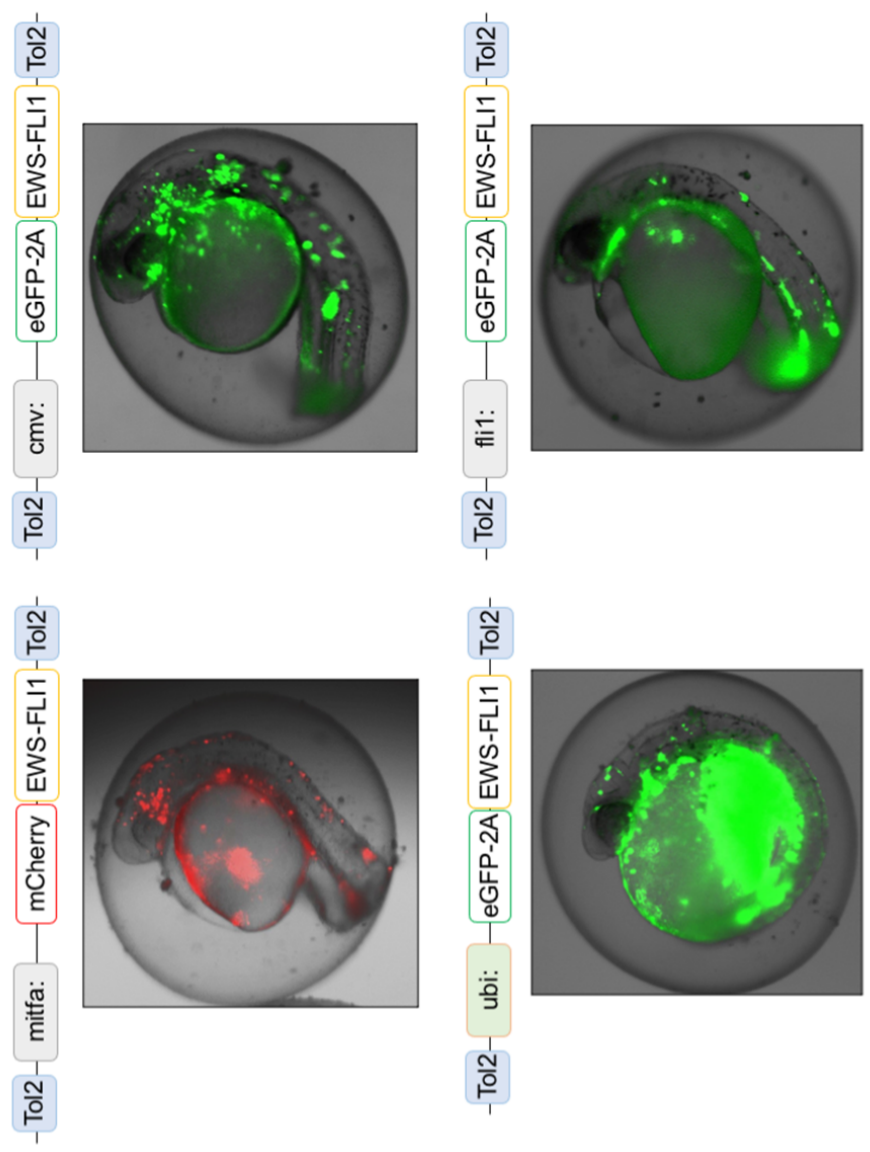

B

Cre-inducible expression
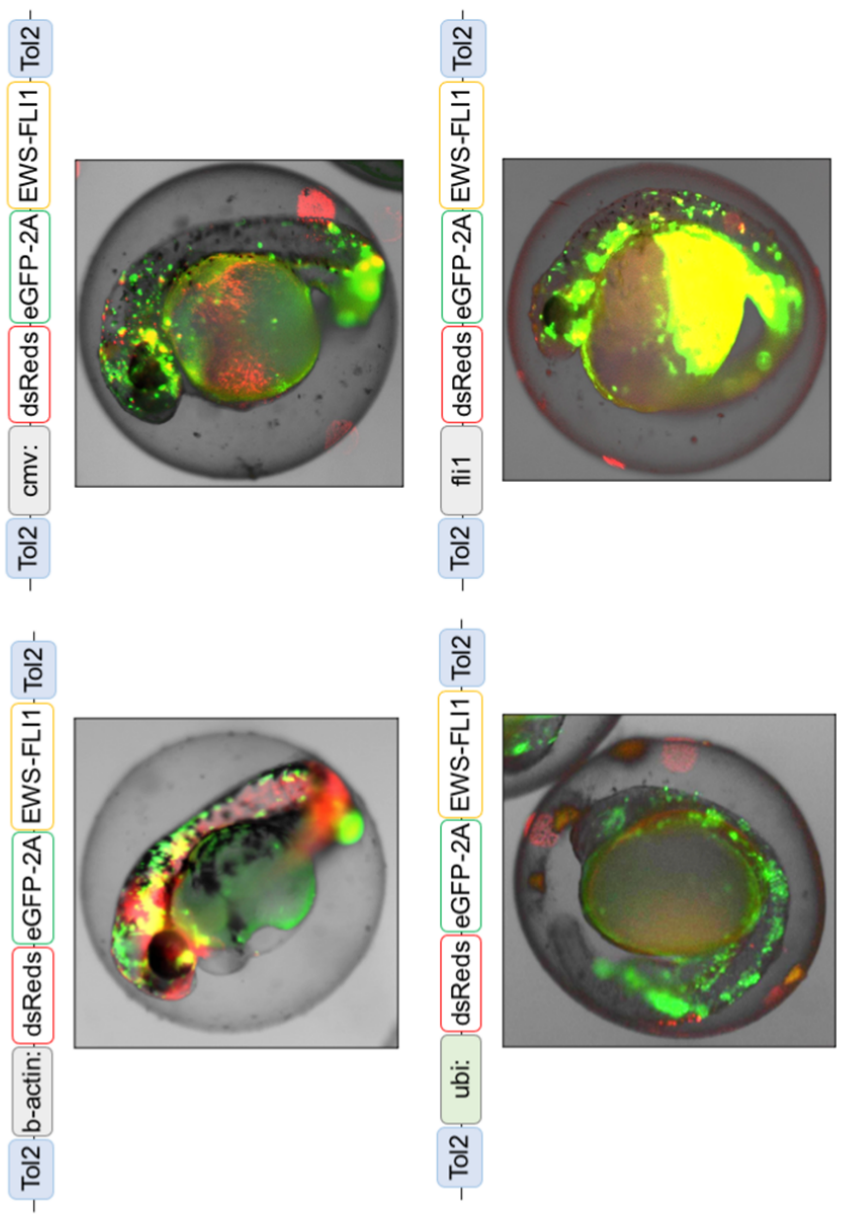


\section{Sup. Figure 2}

A

Control

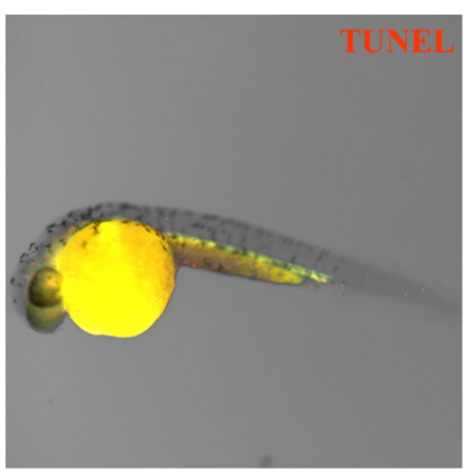

b-actin: RSG-EWSR1-FLI1

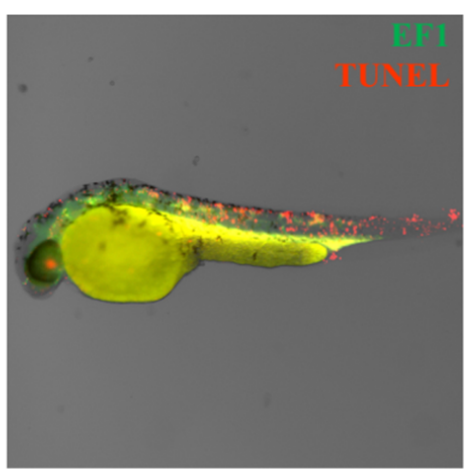

36 hpf

B

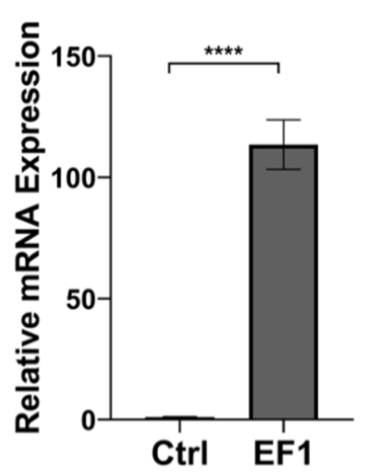

C

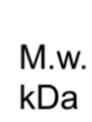

kDa

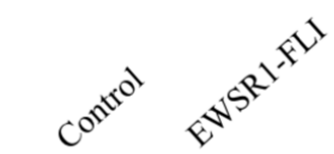

67-

57-

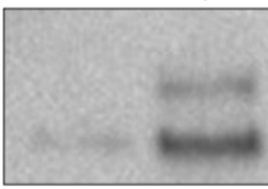

55-

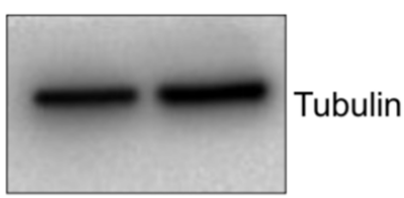

FLI

D

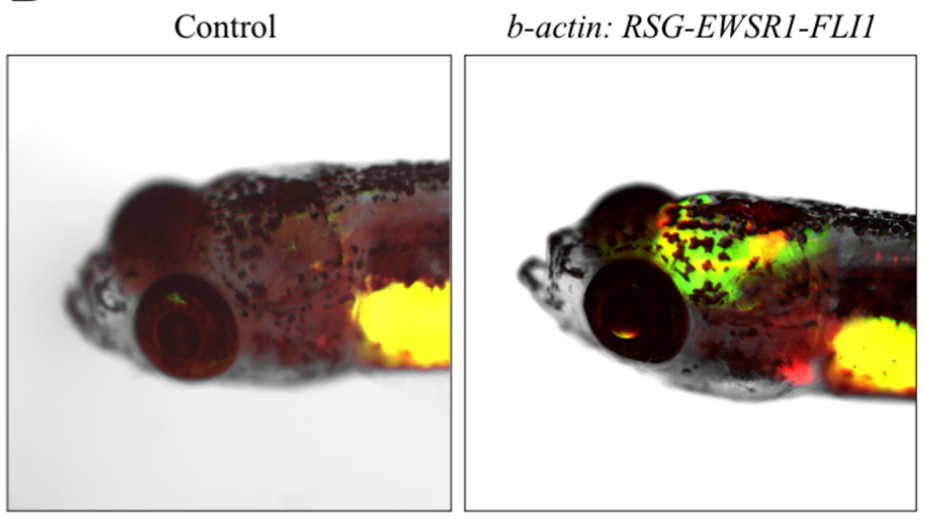

$1 \mathrm{mpf}$

E

Control

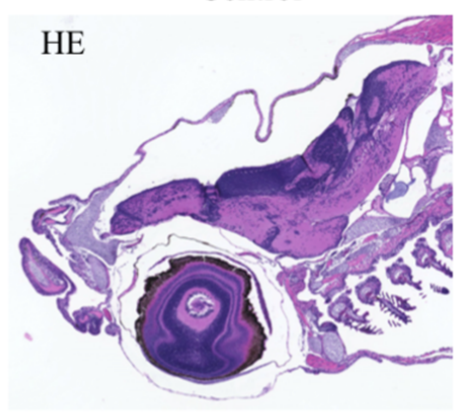

b-actin: RSG-EWSR1-FLI1

HE

EWSR1-FLI1

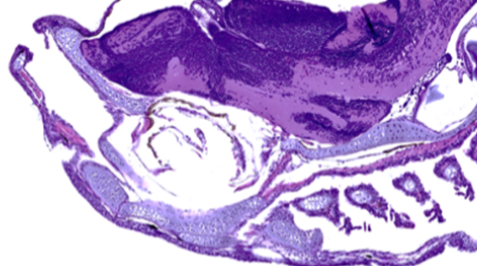

$1 \mathrm{mpf}$ 
Su bioRxizreprint doi: htps://doi.org/10.1101/2021.05.25.445683; this version posted May 27, 2021. The copyright holder for this preprint (which

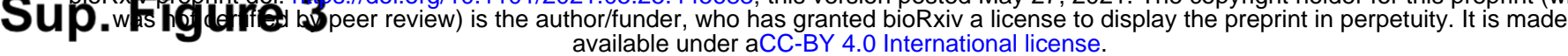

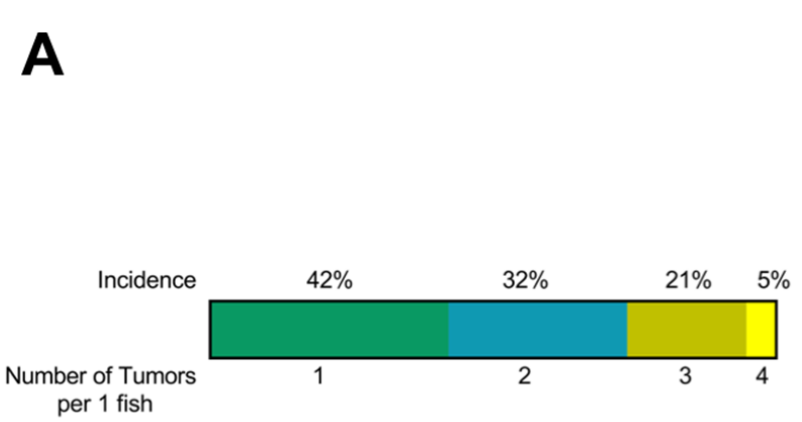

per 1 fish
B

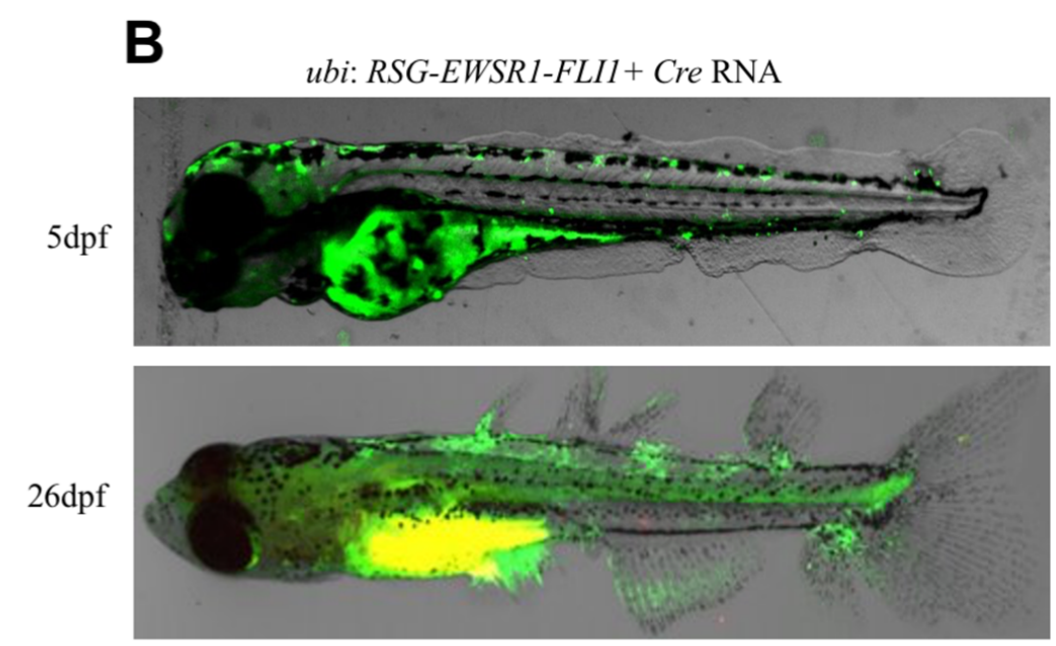

C
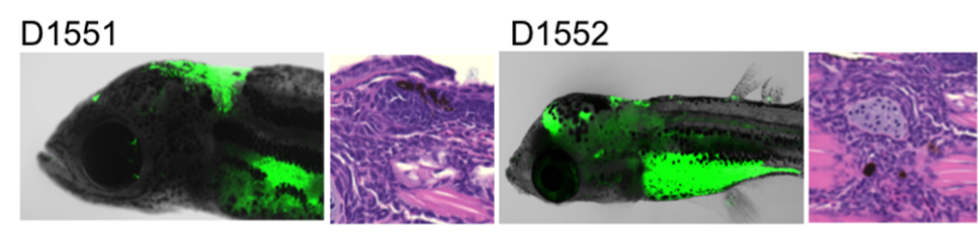

D1553

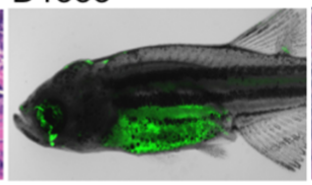

D1558

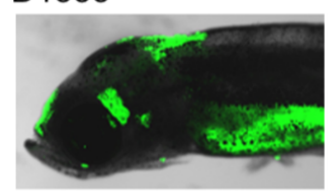

D1560

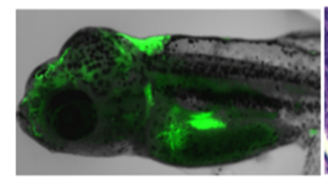

D1565

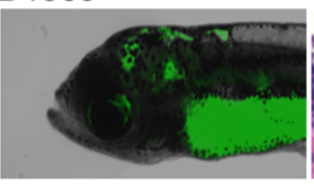

D1571

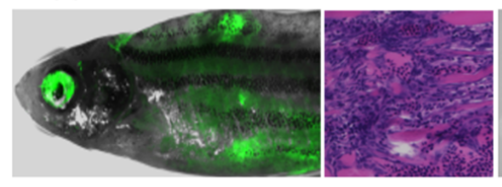

D1610

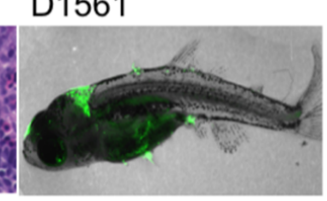

D1566
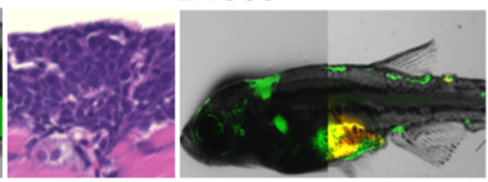

\section{D1610}

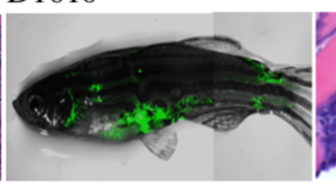

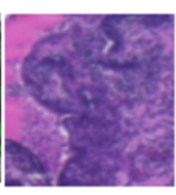

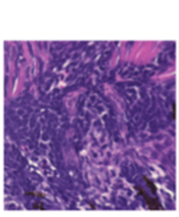

D1562

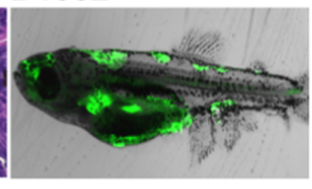

D1567
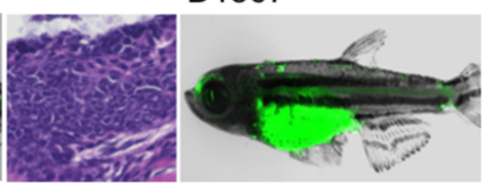

D1611

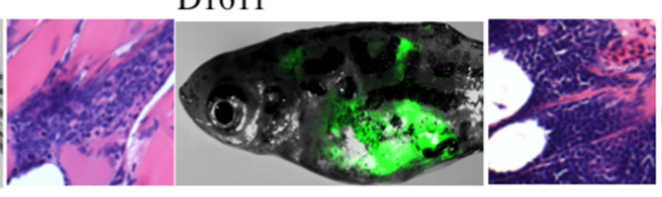

D1612

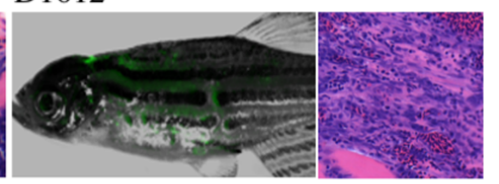

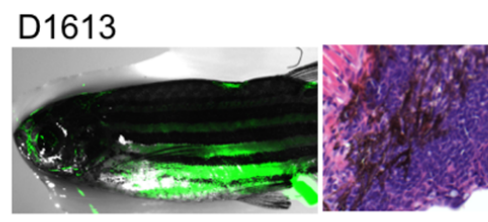

D1614

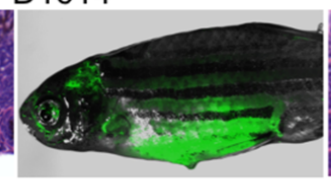

D1616

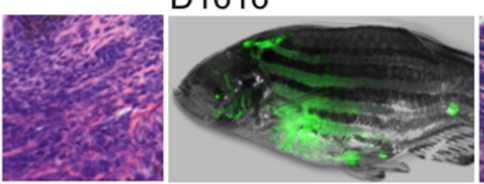

D1554

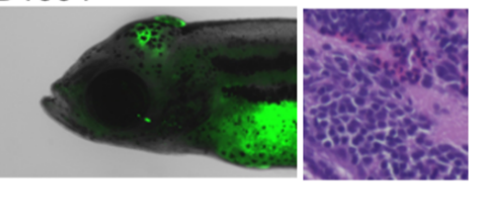

D1559

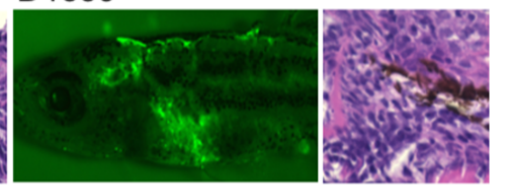

D1563

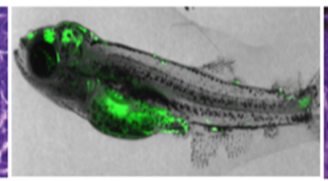

D1570
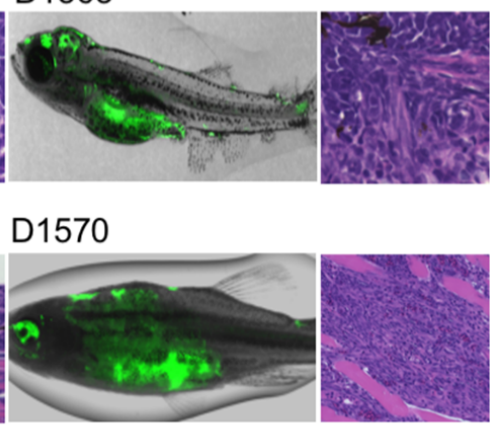
bioRxiv preprint doi: https://doi.org/10.1101/2021.05.25.445683; this version posted May 27, 2021. The copyright holder for this preprint (which was not certified by peer review) is the author/funder, who has granted bioRxiv a license to display the preprint in perpetuity. It is made available under aCC-BY 4.0 International license.

\section{Sup. Figure 4}
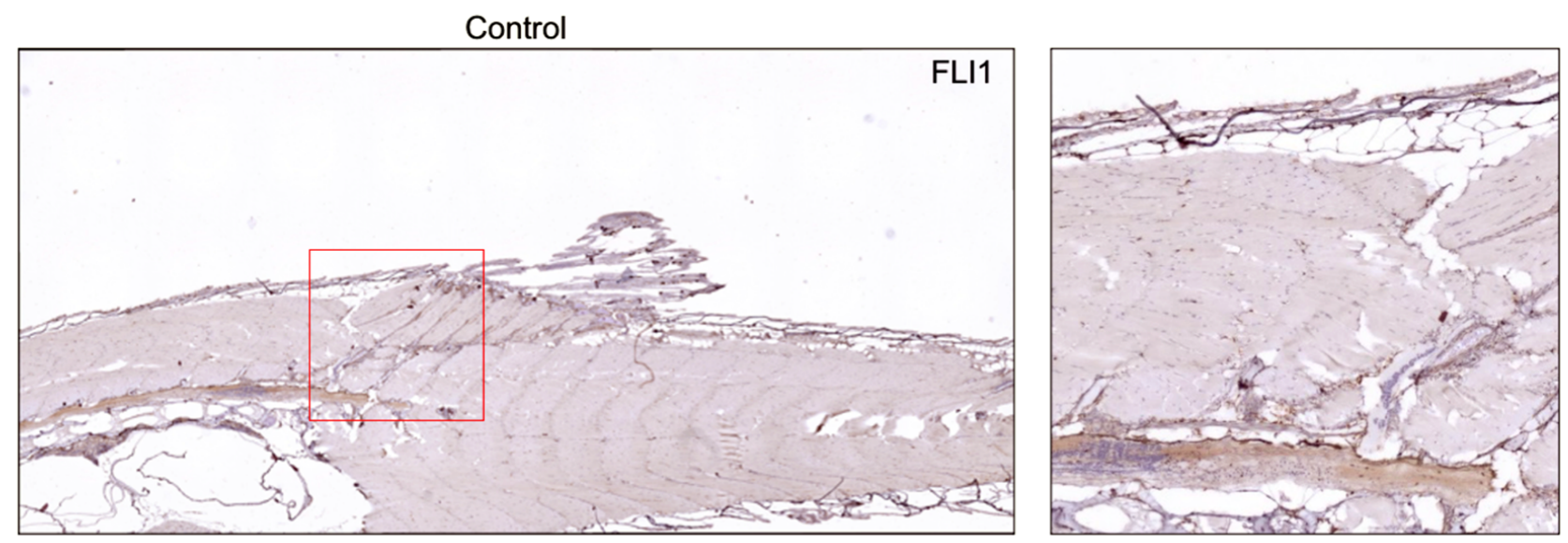

EWSR1-FLI1
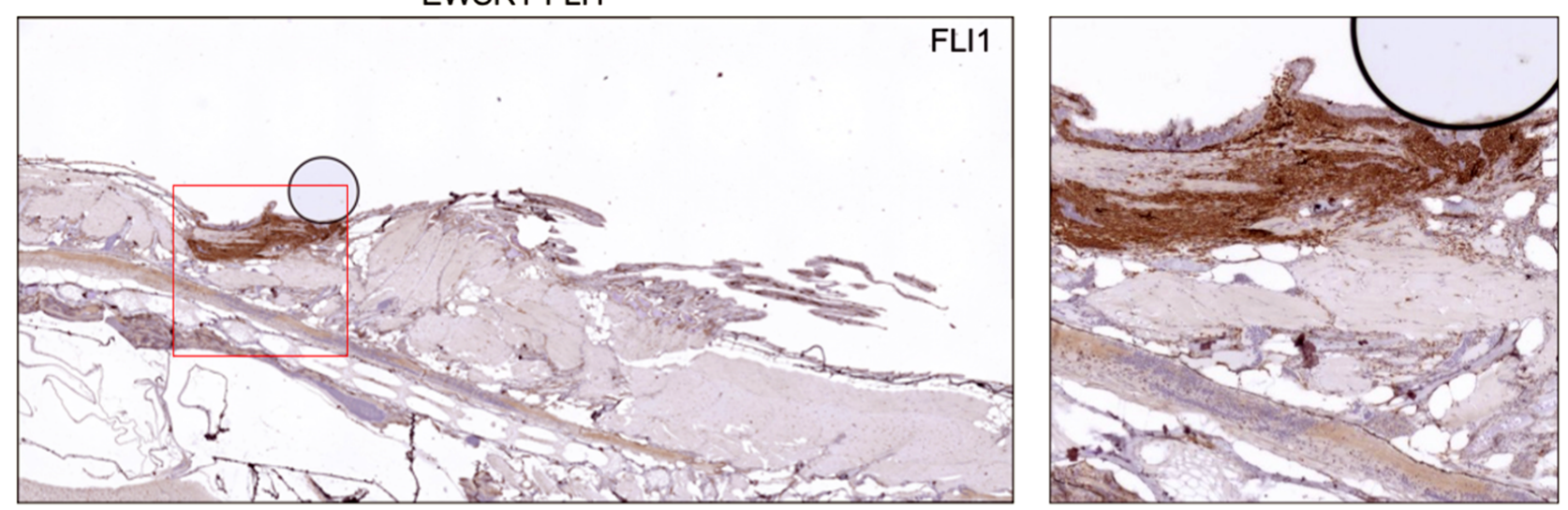
bioRxiv preprint doi: https://doi.org/10.1101/2021.05.25.445683; this version posted May 27, 2021. The copyright holder for this preprint (which was not certified by peer review) is the author/funder, who has granted bioRxiv a license to display the preprint in perpetuity. It is made available under aCC-BY 4.0 International license.

\section{Sup. Figure 5}

A
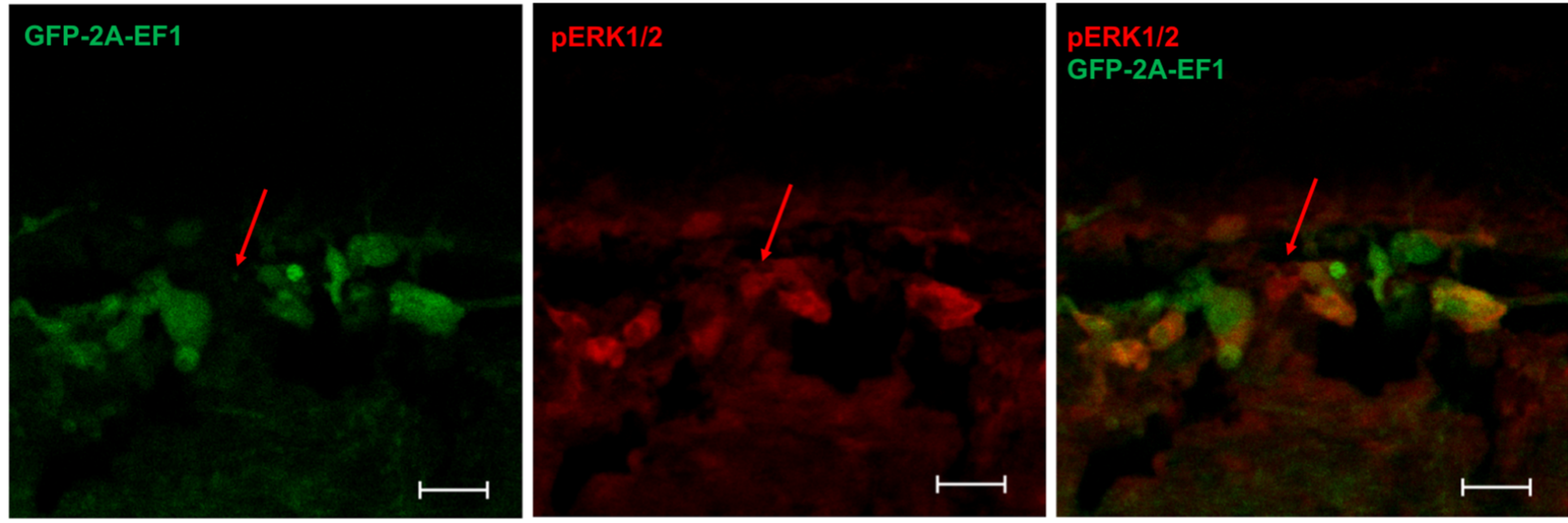

B
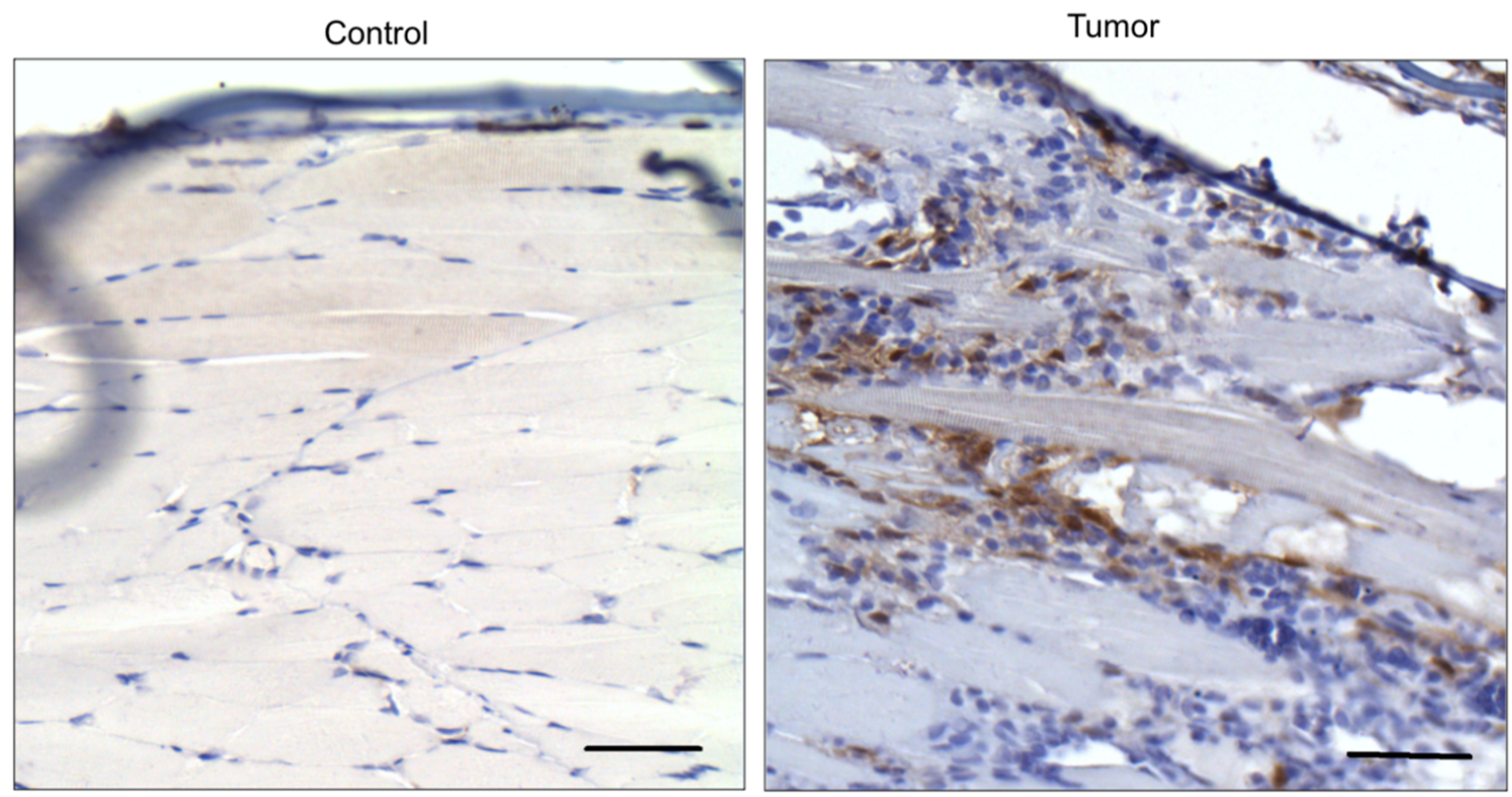